Special Issue "Recent Developments in International Money and Finance" Editor: Ronald MacDonald

\title{
A Model of the IMF as a Coinsurance Arrangement
}

\author{
Ralph Chami, Sunil Sharma, and Ilhyock Shim \\ Internatinal Monetary Fund; Internatinal Monetary Fund; Bank for International Settlements
}

\begin{abstract}
:
The paper shows that an IMF-like coinsurance arrangement among countries can play a useful role in the global financial system. The operation of the coinsurance arrangement is examined under different loan contracts. It shows that, if the IMF's objective is to safeguard its resources and be concerned about the welfare of the borrower, an ex ante loan contract is more likely to create the right incentives than an ex post loan contract. Such contracts highlight the need for precommitment to contend with the Samaritan's dilemma and time inconsistency, and state-contingent repayment schemes to deal with King Lear's dilemma.
\end{abstract}

JEL: D82, F02, F33, G22

Keywords: IMF; coinsurance arrangement; moral hazard; Samaritan's dilemma; King Lear's dilemma

Correspondence: Ilhyock Shim, Representative Office for Asia and the Pacific, Bank for International Settlements, 78th floor, Two International Finance Centre, 8 Finance Street, Central, Hong Kong, Tel: +852-2878-7147, Fax: +852-2878-7123.

The authors would like to thank Lorenzo Bini Smaghi, Sajjid Chinoy, Tom Cosimano, Burkhard Drees, Jeff Fischer, Connel Fullenkamp, Rex Ghosh, Hervé Hannoun, Mohsin Khan, Tim Lane, Jaewoo Lee, Leslie Lipschitz, Alan MacArthur and Miguel Messmacher for comments. Tala Khartabil provided superb research assistance. The views expressed in this paper are those of the authors and do not necessarily reflect the views of the BIS, the IMF, or the policy of these institutions. The remaining errors are those of the authors. 


\section{Introduction}

Financial liberalization, capital account convertibility, and the increasing importance of private capital flows have dramatically changed the international environment in which the IMF operates. For many countries, access to international capital markets has brought opportunities for loosening funding constraints and underpinning more ambitious growth strategies, as well as developing financial institutions that can hold their own in the international financial arena. However, these opportunities have come with new attendant hazards - a greater exposure to international liquidity cycles, changes in the moods and expectations of foreign investors, contagion, and external shocks in general. And the financial crises of the last decadeMexico (1994), Thailand (1997), Korea (1997), Indonesia (1997), Russia (1998), Brazil (1999), and Argentina (2001-02) - have shown that when there is a massive withdrawal of external financing, the cost to the economy can be punitive, and the demand for IMF resources can be huge by the standards of earlier decades.1

These large IMF programs have reopened the debate on the nature and role of IMF financing. Some observers argue that recourse to IMF financing generates moral hazard on the part of both borrowers and lenders - leading to less due diligence by private lenders, and allowing borrowers to incur larger debts and get by with weaker policies and institutions. Hence, IMF financing, though offering a cushion in times of financial crises, increases the likelihood of such events occurring. Others argue that the moral hazard associated with international financial support is limited and that the focus should be on containing the real hazards generated by the structural and policy deficiencies of emerging markets and their pernicious interaction with the global financial system. Markets do not always work to provide appropriate discipline, the extent of access and the lending terms may not be justified by fundamentals, and when problems are eventually recognized, markets may impose punishments that are overly severe ${ }^{2}$

The rationale for IMF financing has remained the same - overcoming market imperfections and enhancing the world's ability to provide international public goods that would otherwise be in short supply $\left.\right|^{3}$ There are a number of factors that lead to

\footnotetext{
${ }^{1}$ See, for example, Jeanne and Zettlemeyer (2001), Ghosh et al. (2002), Haldane and Taylor (2003), and Independent Evaluation Office (2003).

${ }^{2}$ For a discussion see Bordo and Schwartz (1999), Calomiris (1999), Mussa (1999), Meltzer et al. (2000), Jeanne and Zettlemeyer (2001), the recent review by Haldane and Taylor (2003) and references therein.

${ }^{3}$ See, for example, Masson and Mussa (1995) and Krueger (1998). Also, see Cordella and LevyYeyati (2004) who argue that the insurance provided to countries by the presence of the IMF may encourage long-term reforms in developing economies.
} 
countries being rationed or excluded from international financial markets: imperfect information about country prospects and institutions, problems related to enforcing sovereign loan contracts, and coordination problems among lenders. On the supply of public goods, just as openness to trade is considered an international public good worth cultivating, a cautious openness to international financial markets also contributes to the development of countries and to the common good. By providing funds temporarily to deal with external payment difficulties so that countries do not adopt policies that are destructive of national and international prosperity, the IMF supplements private markets when necessary, and helps countries to become more open to trade and capital. It enables countries to bear the risks associated with reforming and developing their financial systems and economies, and opening them to achieve a more efficient global allocation of resources.

This paper uses a stylized framework to examine the role of an IMF-like institution in the world financial system. First, it shows that a coinsurance arrangement among countries can, in principle, play a useful role in helping countries bear the risks involved in developing their economies and becoming part of the global financial system $4^{4}$

Second, the paper tries to model the operation of the coinsurance arrangement by examining the nature and timing of interventions. The question asked is: how should the loan contract between a borrowing country and the IMF be structured and when should the contractual details be decided to create the right incentivesencourage countries to take prudent risks, do their best to prevent external payment imbalances from emerging, and should they run into trouble take the policies to

\footnotetext{
${ }^{4}$ In this paper, we use the term "coinsurance" synonymously with "mutual insurance." The coinsurance arrangement can be thought of as an emergency lender envisaged in Fischer (1999), who makes the case that such an institution need not have the power to create money, as long as it has the resources to play a useful role as crisis lender and manager. For a more traditional interpretation of the lender-of-last-resort see, for example, Capie (1998).

${ }^{5}$ The Chiang Mai Intitiative among the ASEAN countries, China, Japan, and Korea can be thought of as a coinsurance arrangement designed to alleviate temporary liquidity shortages. Member central banks can swap their own currencies for certain international currencies for a short period of time. The size of the "borrowing" can be some multiple of the amount committed by the member under the arrangement. Note also that the original conception of the IMF was based on the idea that most countries would be both creditors and debtors to the IMF over time. In the 1950s and 1960s, with the exception of Germany and the United States, most members fit this description and at some point used IMF resources to help fix external payment imbalances. However, by the 1980s most industrial countries had begun to rely exclusively on private capital flows, and the IMF membership became divided into creditor and debtor groups (see, Boughton (2004)).
} 
rectify the situation. Should the IMF commit to a predetermined contract or should the contractual details be decided ex post after the country is in crisis?

To examine these issues, we use a two-period repeated moral hazard setting in a principal-agent framework (with the IMF being the principal and the borrowing country the agent).$^{6}$ The problem is examined under two distinct objectives for the IMF: (i) safeguarding of its resources and (ii) a concern for the borrowing country's welfare. If the country runs into trouble, the IMF provides funding over the two periods - a tranche in each period. After the two periods the IMF is paid back by the country. The IMF cannot observe the policy effort but can observe the country's output performance. A higher policy effort in the first period increases the probability of avoiding a crisis, and should the country get into one, a higher policy effort in the second period increases the probability of recovery.

In our model, the IMF and the member country take sequential decisions to maximize their respective utilities. Three cases are considered for the timing of IMF intervention: (i) the ex ante contract, where the IMF precommits to a contingent loan contract for the two periods - the contract specifies the first and second tranches before the country has chosen its policy in the first period; (ii) an ex post contract, where the IMF chooses the contract after the country has chosen its policy effort in the first period and fallen into a crisis - the contract specifies the first and second loan tranches after observing the outcome in the first period; and (iii) a variation on the preceeding ex post contract, where the IMF chooses the first tranche after observing that the country is in a crisis and then chooses the second tranche after observing the output of the program country.

The size and design of the IMF loan contract turns out to depend crucially on the objectives of the Fund and the timing of Fund intervention. If the Fund were to be concerned only with safeguarding its resources, then it would demand full repayment irrespective of the country's situation. However, if in addition to safeguarding its resources, the Fund also cares about the welfare of its borrowers, the contractual repayment scheme in the second period is in general contingent on the economic situation of the country.

The size of the first tranche lowers the policy effort both for avoiding a crisis as well as for overcoming one. This is because the first tranche has to deal with two dilemmas in our setting, the Samaritan's dilemma and King Lear's dilemma.7

\footnotetext{
${ }^{6}$ See, for example, Laffont and Martimort (2002) and references therein.

${ }^{7}$ For a discussion of these dilemmas and related issues, see for example, Becker (1974), Buchanan (1975), Hirshleifer (1977), Bernheim, Shleifer and Summers (1985), Cox (1987), Bergstrom (1989), Bruce and Waldman (1990), Chami (1996, 1998) and Jurges (2000).
} 
The first tranche, which is given after a country chooses its effort in the first period, lowers the incentives for preventing a crisis because the country knows that the IMF cares about its welfare and will provide a cushion in a crisis - the Samaritan's Dilemma (Buchanan, 1975). On the other hand, providing the first tranche before the country decides on policy in the second period does not create the right incentives for a program country to solve the crisis. Once the first tranche is delivered, the country's choice of policy in the second period need not be optimal from the IMF's perspective - King Lear's dilemma (Hirshleifer, 1977). We argue that to deal with these dilemmas it is best for the IMF to commit to an ex ante contract - that is, design and offer the contract before a crisis arises. Such a contract specifies the first tranche and the state-contingent second tranche, penalizing the country for low output, but rewarding it if the output is high and the country emerges from crisis.

In the presence of information asymmetries and given the mandate of the IMF to safeguard its resources and care about the welfare of members, the timing of a Fund program has a critical effect on the country's effort to avoid a crisis, and on its effort to recover from a crisis. We show that ex post contracts - that is, IMF intervention after a country has fallen into crisis - does not elicit the highest policy effort from a country. In such cases, the program country is likely to reduce its effort to recover from the crisis, knowing that if it does not recover, a suitable loan will be available from a "caring" Fund. In contrast, deciding on the IMF program ex ante tends to result in higher effort by the country to avoid and to recover from a crisis. However, we show that such a contract is subject to time-inconsistency problems, as the Fund and the country may both find it in their interest to renegotiate the Fund's ex ante contract, once the country enters into a crisis. Hence, it may be best for the Fund to precommit to a loan contract, raising the interesting question of how such a precommitment can be enforced.

The rest of the paper is organized as follows: Section 2 considers a model of coinsurance with endogenous risks and moral hazard. Section 3 deals with the operation of the coinsurance arrangement and the optimal choice of loan contracts for the IMF and member countries. The last section concludes. Proofs of all results are given in the Appendix.

\section{A Model of Coinsurance}

In this section, we consider the possibility of voluntary coinsurance between two countries under moral hazard. The two countries $i$ and $j$ are subject to an income shock (for example, a crisis). In particular, two states of nature, good $(G)$ and bad 
$(B)$, occur with probability $(1-\pi)$ and $\pi$, respectively, where $0<\pi<1$. If the good state prevails, country $i$ receives income $y_{i}(G)=y_{i}$, and if a country suffers an adverse shock, country $i$ receives income $y_{i}(B)=y_{i}-\delta_{i}$. The probability $\pi$ of being subjected to an adverse shock is a function of the country's policy efforts to decrease vulnerability to shocks - that is, policies conducive to economic growth, macroeconomic and political stability, and a healthy financial sector. The policy effort is represented by the symbol $e$, with higher policy effort reducing the probability of the bad outcome. We assume such effort is private information, which is not fully revealed to an outside observer (or the other country). Let the effect of policy on the probability of the bad outcome be given by $\pi(e)$, a convex function, i.e. $\pi^{\prime}<0$, $\pi^{\prime \prime}>0$. However, policy actions that can lower the probability of a bad outcome are "costly", and the disutility from undertaking such actions is denoted by $v(e)$, where $v(\cdot)$ is a convex function, i.e. $v^{\prime}>0, v^{\prime \prime}>0$. For simplicity, a country's utility function is additive and separable, and given by

$$
U_{i}\left(y_{i}, e_{i}\right)=u_{i}\left(y_{i}\right)-v_{i}\left(e_{i}\right)
$$

where $u(\cdot)$ is a continuously differentiable concave function with $u^{\prime}>0$ and $u^{\prime \prime}<0$.

Consider the case where the two countries coinsure each other: if country $i$ is hit by a shock but country $j$ is not, then $j$ transfers $\beta$ to $i$, and the reverse happens when $j$ suffers a shock and $i$ does not. If both countries are hit by shocks, then there is no net transfer. There are four possible outcomes under this coinsurance arrangement. The expected utility for country $i$ is given by:

$$
\begin{aligned}
E\left(U_{i}\right)= & \left(1-\pi_{i}\left(e_{i}\right)\right)\left(1-\pi_{j}\left(e_{j}\right)\right) u_{i}\left(y_{i}\right)+\left(1-\pi_{i}\left(e_{i}\right)\right) \pi_{j}\left(e_{j}\right) u_{i}\left(y_{i}-\beta\right) \\
& +\pi_{i}\left(e_{i}\right)\left(1-\pi_{j}\left(e_{j}\right)\right) u_{i}\left(y_{i}-\delta_{i}+\beta\right)+\pi_{i}\left(e_{i}\right) \pi_{j}\left(e_{j}\right) u_{i}\left(y_{i}-\delta_{i}\right)-v_{i}\left(e_{i}\right) .
\end{aligned}
$$

In addition to symmetry $\left(\pi_{i}=\pi_{j}=\pi, u_{i}=u_{j}=u, y_{i}=y_{j}=y, \delta_{i}=\delta_{j}=\delta\right)$, we make the following assumptions:

(i) $\beta \geq 0$, that is, when one country suffers a shock and the other does not, the former receives a positive transfer from the latter;

(ii) $y-\delta+\beta \leq y-\beta$, that is, under the coinsurance arrangement each country has at least as much income in the good state compared to that in the bad state. In the symmetric case, this implies that $\beta \leq \delta / 2$.

(iii) Nash assumption, that is, each country maximizes utility taking $\beta$ and the effort of the other country as given. For country $i$, the first order condition with 
respect to $e_{i}$ is

$-\pi_{i}^{\prime}\left(1-\pi_{j}\right) u_{i}\left(y_{i}\right)-\pi_{i}^{\prime} \pi_{j} u_{i}\left(y_{i}-\beta\right)+\pi_{i}^{\prime}\left(1-\pi_{j}\right) u_{i}\left(y_{i}-\delta_{i}+\beta\right)+\pi_{i}^{\prime} \pi_{j} u_{i}\left(y_{i}-\delta_{i}\right)-v_{i}^{\prime}=0$

and a similar condition holds for country $j$. Together, these two reaction functions provide the optimal (Nash) policy efforts for the countries: $e_{i}=e_{i}\left(\beta, e_{j}\right)$ and $e_{j}=$ $e_{j}\left(\beta, e_{i}\right)$. By symmetry, we get the equilibrium policy effort levels: $e_{i}^{*}=e_{j}^{*}=$ $e^{*}(\beta)$. In this setup, it is known that, if income risk is endogenous, larger income transfers under the coinsurance arrangement reduce the policy effort to prevent the bad outcome i.e. $\left[\frac{\partial e^{*}}{\partial \beta}\right]<0$, but that countries value coinsurance even in the presence of moral hazard.

So far, a country cared only about its own utility under the coinsurance arrangement. Now let's posit that a country also cares about what happens to the other country in a coinsurance arrangement. The interdependence of countries in international trade, financial markets, and through the coinsurance arrangement may make them concerned about the macroeconomic and financial health of the other country. Thus, country $i$ may care about the utility of country $j$ and vice versa.

To capture the interdependence among countries, we specify the utility function as

$$
\begin{aligned}
U_{i}\left(y_{i}, e_{i}, U_{j}\right) & =u_{i}\left(y_{i}\right)-v_{i}\left(e_{i}\right)+\lambda_{i} U_{j}\left(y_{j}, e_{j}\right) \\
U_{j}\left(y_{j}, e_{j}, U_{i}\right) & =u_{j}\left(y_{j}\right)-v_{j}\left(e_{j}\right)+\lambda_{j} U_{i}\left(y_{i}, e_{i}\right)
\end{aligned}
$$

where $\lambda_{i}$ and $\lambda_{j}$ are parameters that depict the concern countries have for each other.

The natural question to ask is what effect the interdependence of country utilities has on the extent of moral hazard $\left.\right|^{8}$ The following lemma and proposition show under what circumstances moral hazard can be mitigated.

Lemma 1 Suppose the two countries in the coinsurance arrangement are identical in all respects, including $\lambda_{i}=\lambda_{j}=\lambda$. Then, as $\lambda \rightarrow 1,\left[\frac{\partial e^{*}}{\partial \beta}\right]_{\lambda \rightarrow 1}=0$.

The intuition for this result is as follows: when identical countries are perfectly altruistic $(\lambda=1)$ and show the same amount of concern for the other country as they do for themselves, their marginal utilities in each state will tend to equality and thus a coinsurance arrangement does not create moral hazard. Each country

\footnotetext{
${ }^{8}$ See, Chami and Fischer (1996) for a similar result in the context of insurance markets.
} 
fully internalizes the externality imposed on the other country. This result, however, crucially depends on the symmetry of the problem.

Proposition 1 Suppose the two countries in the coinsurance arrangement are identical in all respects, except for the size of their current income (i.e. $y_{i}>y_{j}$ ). Then, even as $\lambda \rightarrow 1,\left[\frac{\partial e^{*}}{\partial \beta}\right]_{\lambda \rightarrow 1} \neq 0$.

If the two countries have different sizes, even though they are identical in all other respects, including the extent of their concern for each other, the marginal utilities in each state are not the same, and thus the externality generated by the coinsurance arrangement cannot be fully internalized $!^{9}$ Lemma 1 and Proposition 1 show that the moral hazard problem can be reduced if the countries in a coinsurance arrangement are concerned about each other's welfare, but that it is difficult to eliminate it. Hence, in the absence of such concern for each other's welfare or in the presence of asymmetry among countries, we may need other mechanisms to mitigate the moral hazard problem in a coinsurance scheme.

The IMF can act as a delegated monitor, provide loans to countries facing external imbalances, and achieve this goal more efficiently. The group of countries in the coinsurance arrangement may find it in their interest to form an institution, say the IMF, that functions as a delegated monitor. The moral hazard problem implicit in a collective insurance arrangement can be contained by a rigorous system of surveillance of all members by the IMF. The more intense and accurate the monitoring, the better the functioning of the coinsurance scheme.

The IMF can also provide temporary liquidity to countries who have suffered an adverse income shock. In this sense, the IMF may have to function as a financial intermediary. The difference is that the IMF does not take deposits but uses resources from a fund created by contributions from member countries. Since the fund is meant to be a revolving one, the IMF provides resources only under adequate safeguards.

Coinsurance is based on a mutual agreement to insure each other against shocks or crises. Hence, it is natural to ask whether an insurance fund needs to be established ex-ante with upfront member contributions or quotas. Creating such a fund ex ante can have certain advantages:

1. Enforcement issues in forming a fund ex post: Even though countries agree to insure each other ex ante, those countries that are not subjected to a shock may, ex post, delay or refuse to pay the contributions they promised. More importantly, since

\footnotetext{
${ }^{9}$ Rajan and Zingales (2000) also make a similar point when they show that the existence of inequalities in opportunities or endowments reduces cooperation.
} 
this coinsurance arrangement is between sovereigns, the international community has only limited means to make a country pay its promised contribution. Under an ex-post coinsurance scheme, the only punishment would be to exclude a non-paying member from the coinsurance group and deprive it of insurance in the future. Hence, setting up a fund ex ante, with insurance only available to participating members, would make clear the resources available.

2. Quick response to the liquidity needs of member countries: Contagion from countries in crises to others is a central issue in international financial markets. Containing such contagion is important, since otherwise a localized or regional shock may spread and lead to systemic problems in the international financial system. Thus, to prevent contagion and maintain confidence in the system, the coinsurance scheme should be able to take prompt actions in the aftermath of a country or regional crisis. To this end, it makes sense to have sufficient liquid funds available to intervene promptly if it is deemed necessary.

3. Reduction in transaction costs: If there is no fund available ex ante, then every time a crisis occurs the collection of contributions from member countries could entail huge transaction costs. On the other hand, if countries set up a fund ex ante, when a country runs into trouble, liquidity can be provided from this fund directly, reducing the costs of putting together emergency financing packages.

\section{Operating the Coinsurance Arrangement}

In the previous section, we showed that countries may find it in their interest to operate a global coinsurance scheme, with the IMF functioning both as a delegated monitor and as a provider of temporary liquidity to countries with external payment imbalances. Clearly, the success of this coinsurance arrangement depends critically on ensuring that recourse to IMF funds does not allow countries to slacken their efforts in making their economies more resistant to shocks, or should crises occur, allow policy makers to postpone measures necessary for a speedy recovery, and hence repayment to the IMF. This section deals with the question of designing loan programs to provide the appropriate incentives to member countries ${ }^{10}$ To answer this question, first we must be clear about the IMF's objectives. Having specified the objective function, we examine different lending contracts for IMF loans. Should the IMF precommit to a loan contract ex ante? Or should the loan amount and contract be assessed and formulated ex post, that is, when the country approaches

\footnotetext{
${ }^{10}$ Note that this section does endogenize the existence of a coinsurance arrangement as an appropriate mechanism, which would be an interesting topic for future research.
}

www.economics-ejournal.org 
the IMF for resources?

As in the previous section, moral hazard arises from the specification that the IMF does not observe the costly policy effort by a country (to reduce the probability of a bad outcome), but only observes the outcomes of the policy actions taken 11

\subsection{A Model of IMF Lending}

In our model, the IMF and the member countries take sequential decisions as shown in Figure 1.

1. The IMF offers a state-contingent lending contract $\left\{I_{1}, I_{2}^{L}, I_{2}^{H}, Z^{L}, Z^{H}\right\}$ consisting of five elements: $I_{1}$ is the first tranche of the IMF loan made available if a country enters a crisis; $I_{2}^{L}, I_{2}^{H}$ are the values of the second loan tranche conditional on whether (post-crisis) output is low (state $L$ ) or high (state $H$ ); $Z^{L}, Z^{H}$ are the state-dependent repayments to the IMF at the end of period $22^{12}$

2. A country chooses policy actions $e_{1}$ to foster growth, macroeconomic stability and prevent crises.

3. Nature roles the dice and a country enters a crisis with probability $\pi\left(e_{1}\right)$ that is dependent on the country's policy actions $e_{1}$. The probability function $\pi\left(e_{1}\right)$ is a decreasing convex function of $e_{1}$. The income level is $y_{1}^{H}$ when there is no crisis, but falls to $y_{1}^{L}$ if there is a crisis and the country does not seek IMF help. It is assumed that $e_{1}$ is private information and not observed by the IMF.

4. If the country faces a crisis and seeks IMF help, it is given the first loan tranche $I_{1}$. After receiving the first tranche, the country chooses policy actions $e_{2}$ to remedy the country's economic situation. $e_{2}$ is private information and not observed by the IMF.

5. Nature plays again, and the country has either a low output $y_{2}^{L}$ with probability $\pi\left(e_{2}\right)$ or a high output $y_{2}^{H}$ with probability $\left[1-\pi\left(e_{2}\right)\right]{ }^{13}$ After the output is observed, the IMF releases the second tranche- $I_{2}^{L}$ if the output is low and $I_{2}^{H}$ if the output is high.

6. At the end, the country pays back the IMF $-Z^{L}$ if low output was observed

\footnotetext{
${ }^{11}$ More realistically, we could assume instead that the IMF imperfectly observes a country's policy effort. This may reduce the scope for moral hazard, but the qualitative results would not change.

${ }^{12}$ The tranches and the size of the loan are the only dimensions of conditionality considered here. It would be interesting to consider other aspects of conditionality in future research.

${ }^{13}$ Note that for notational simplicity we use the same probability function $\pi(\cdot)$ for both efforts. Of course, we could specify the functions as differing over countries and efforts, but this merely adds to notational complexity without providing any additional insight.
} 
Figure 1. A Model of IMF Lending

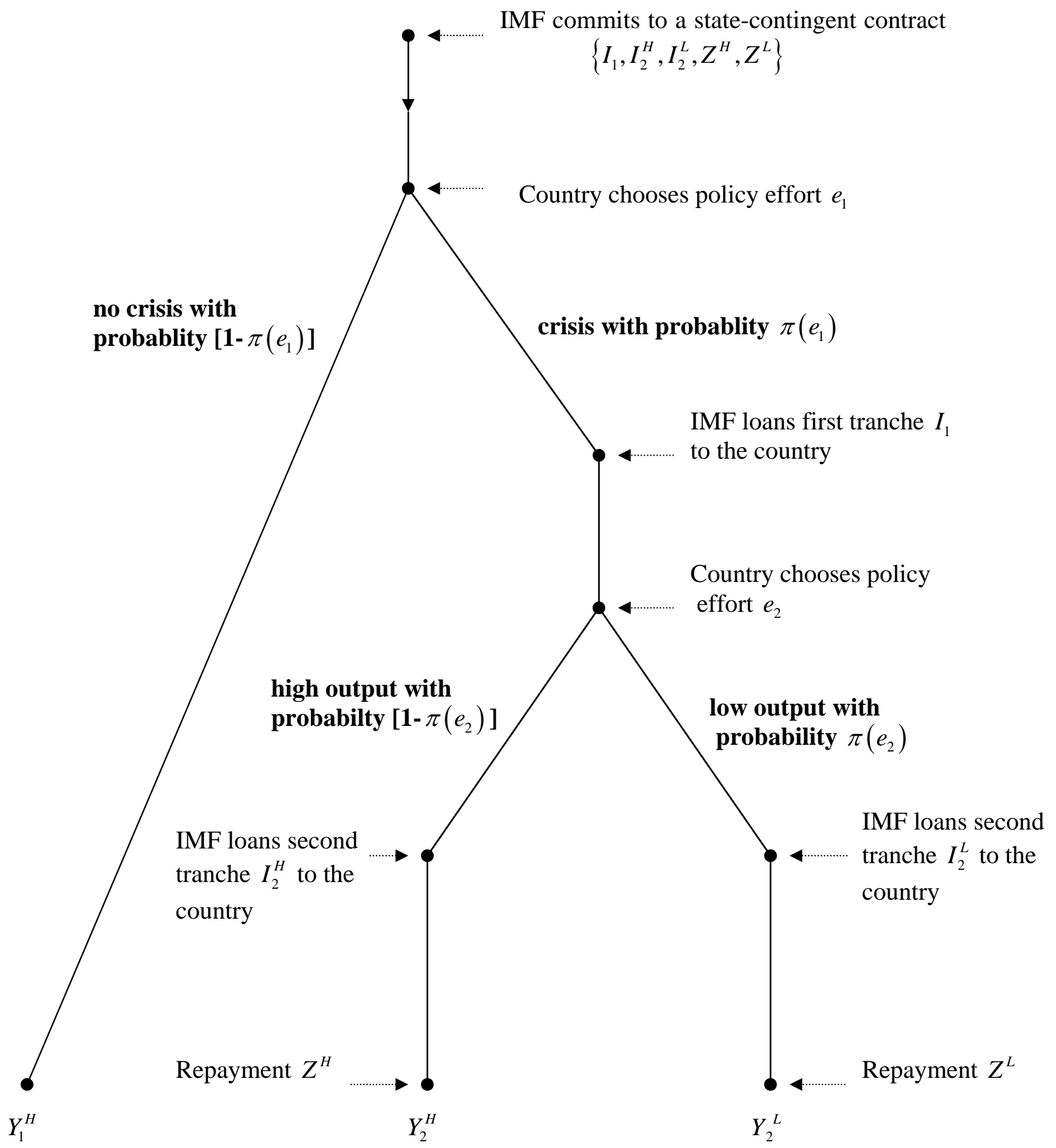


and $Z^{H}$ if the output was high 14

In the above setup, given the state-contingent contract offered by the IMF, the country makes two sequential policy decisions to maximize its utility: it chooses $e_{1}$ when it is, to use the common parlance, a surveillance country, and it chooses $e_{2}$, if it suffers an income shock and becomes a program country.

Note that in this problem, since the country has to make repayment at the end, the contract can be simplified by focusing on the net repayments. Let $z^{L} \equiv Z^{L}-I_{2}^{L}$ and $z^{H} \equiv Z^{H}-I_{2}^{H}$ be the net repayments by the country at the end of the second period. Hence, the IMF's state-contingent contract can be defined in terms of three variables $\left\{I_{1}, z^{L}, z^{H}\right\}$

To simplify matters, the following assumptions are made without loss of generality:

1. A zero interest rate is charged on the IMF loans, 15

2. $y_{2}^{L} \geq z^{L} ; y_{2}^{H} \geq z^{H}$. In the second period, the country is able to the make the net repayment only if it has sufficient income.

3. The first tranche $I_{1}$ is bounded below by $q$, and bounded above by a multiple of $q$, say $n q$, or the resources available to the IMF, $x$. We can interpret $q$ as the country's quota (contribution to the coinsurance fund).

4. $y_{1}^{L} \ll y_{2}^{L}$. This is a sufficient condition for a country that experiences a crisis to seek IMF help.

5. $y_{1}^{H}>\max \left[y_{2}^{L}+I_{1}-z^{L}, y_{2}^{H}+I_{1}-z^{H}\right]$ This condition implies that a country prefers not to fall into a crisis and seek IMF resources.

\subsection{The IMF's Objective Function}

The IMF is endowed with a fixed amount of resources, $x$, that it can use to make contingent loans to the members of the coinsurance arrangement. ${ }^{16}$ The design of the loan contracts and the associated conditionality will depend critically on the objectives of the IMF.

\footnotetext{
${ }^{14}$ The IMF could choose a fixed repayment scheme rather than a state-contingent one. Such a scheme would be a special case of the contract considered.

${ }^{15}$ This assumption is made to simplify the exposition. We could assume that the IMF imposes a levy on its loans to cover its costs of lending. Most IMF lending is subject to a rate of charge, which includes a market-related interest rate and a component to cover the IMF's operational costs. Introducing a rate of charge that allows the IMF to recoup its costs, would not change the qualitative nature of our results. Determining the appropriate rate of charge is beyond the scope of this paper.

${ }^{16}$ Note that the first tranche cannot exceed the amount of resources available to the IMF, so $x \geq I_{1} \geq \max \left(z^{H}, z^{L}\right) \geq 0$.
} 
First, the IMF being the guardian of a revolving coinsurance fund is mandated to lend resources only under adequate safeguards - that the borrowing country will make appropriate use of the funds and, as a consequence, be in a position to repay the IMF over a stipulated time period. This objective implies that the IMF's utility function depends positively on the size of its own resources. We represent this utility function as 17 .

$$
U_{I M F}(x)=\hat{u}(x)
$$

and the expected utility of the IMF under this specification is given by:

$$
E U_{I M F}=\left[1-\pi\left(e_{1}\right)\right] \hat{u}(x)+\pi\left(e_{1}\right)\left\{\pi\left(e_{2}\right) \hat{u}\left(x-I_{1}+z^{L}\right)+\left[1-\pi\left(e_{2}\right)\right] \hat{u}\left(x-I_{1}+z^{H}\right)\right\}
$$

Second, one could argue that the IMF should also show direct concern for the welfare of the borrowing country. Such direct concern of the IMF with the utility of the borrowing country is represented by

$$
U_{I M F}(x, y)=\hat{u}(x)+\theta u(y)
$$

where $u(y)$ is the country's utility function and $\theta$ is the relative weight the IMF attaches to the utility of a borrowing country compared to safeguarding its own resources. The resulting expected utility function is

$$
\begin{aligned}
E U_{I M F}= & {\left[1-\pi\left(e_{1}\right)\right]\left[\hat{u}(x)+\theta u\left(y_{1}^{H}\right)\right]-\theta v\left(e_{1}\right)-\theta \pi\left(e_{1}\right) v\left(e_{2}\right) } \\
& +\pi\left(e_{1}\right)\left\{\pi\left(e_{2}\right)\left[\hat{u}\left(x-I_{1}+z^{L}\right)+\theta u\left(y_{2}^{L}+I_{1}-z^{L}\right)\right]\right. \\
& \left.+\left[1-\pi\left(e_{2}\right)\right]\left[\hat{u}\left(x-I_{1}+z^{H}\right)+\theta u\left(y_{2}^{H}+I_{1}-z^{H}\right)\right]\right\}
\end{aligned}
$$

\subsection{Policy Strategy for the Country}

Assuming that a country's utility depends only on its income, the standard von NeumannMorgenstern expected utility functions for a surveillance country (country $S$ in pe-

\footnotetext{
${ }^{17}$ The utility function of the IMF, $\hat{u}(\cdot)$, and of the country, $u(\cdot)$, are assumed to be strictly concave and satisfy the Inada conditions.
} 
riod 1) and program country (country $P$ in period 2) are:

$$
\begin{aligned}
E U_{S}= & {\left[1-\pi\left(e_{1}\right)\right] u\left(y_{1}^{H}\right) } \\
& +\pi\left(e_{1}\right)\left\{\pi\left(e_{2}\right) u\left(y_{2}^{L}+I_{1}-z^{L}\right)+\left[1-\pi\left(e_{2}\right)\right] u\left(y_{2}^{H}+I_{1}-z^{H}\right)-v\left(e_{2}\right)\right\} \\
& -v\left(e_{1}\right)
\end{aligned}
$$

$$
E U_{P}=\pi\left(e_{2}\right) u\left(y_{2}^{L}+I_{1}-z^{L}\right)+\left[1-\pi\left(e_{2}\right)\right] u\left(y_{2}^{H}+I_{1}-z^{H}\right)-v\left(e_{2}\right)
$$

where the $v$ function representing the cost or disutility of the policy effort satisfies $v(0)=0, v^{\prime}(0)=0$, and $v^{\prime}(\cdot)>0, v^{\prime \prime}(\cdot)>0, \forall e>0$.

Under our assumptions, the IMF is able to induce a strictly positive policy effort $e_{2}^{*}$ from a program country in period 2 , where $e_{2}^{*}$ satisfies the following first-order condition:

$$
\pi^{\prime}\left(e_{2}\right)\left[u\left(y_{2}^{L}+I_{1}-z^{L}\right)-u\left(y_{2}^{H}+I_{1}-z^{H}\right)\right]-v^{\prime}\left(e_{2}\right)=0
$$

Equation (11) equates the marginal utility and the marginal cost of the policy effort to overcome the crisis. Since for $e_{2}^{*}>0, v^{\prime}\left(e_{2}^{*}\right)>0$ and $\pi^{\prime}\left(e_{2}\right)<0$, we have $u\left(y_{2}^{L}+I_{1}-z^{L}\right)<u\left(y_{2}^{H}+I_{1}-z^{H}\right)$ and $u^{\prime}\left(y_{2}^{L}+I_{1}-z^{L}\right)>u^{\prime}\left(y_{2}^{H}+I_{1}-z^{H}\right)$. This implies that, as long as $e_{2}^{*}>0$, under a state-contingent repayment scheme the country's income need not be equalized across the high and the low-income states, i.e. $\left(y_{2}^{L}-z^{L}\right) \neq\left(y_{2}^{H}-z^{H}\right)$. From (11), using the implicit function theorem we derive the effect of each of the contract variables $\left\{I_{1}, z^{L}, z^{H}\right\}$ on the policy effort, $e_{2}^{*}$.

Proposition 2 The larger the first tranche, the smaller is $e_{2}^{*}: e_{2 I_{1}}^{*} \equiv\left(\frac{\partial e_{2}^{*}}{\partial I_{1}}\right)<0$; the larger the net repayment when the income is low, the higher is $e_{2}^{*}: e_{2 z^{L}}^{*} \equiv\left(\frac{\partial e_{2}^{*}}{\partial z^{L}}\right)>0$; the larger the net repayment when the income is high, the smaller is $e_{2}^{*}: e_{2 z^{H}}^{*} \equiv$ $\left(\frac{\partial e_{2}^{*}}{\partial z^{H}}\right)<0$.

Proposition 2 implies that a relatively higher repayment when output is low, provides an incentive for the country to exert higher effort to get out of a crisis. On the other hand, if output is high, requiring a higher repayment from the country, acts like a tax and discourages effort. Another way to interpret the proposition is that an 
IMF loan contract that accommodates low output but penalizes high output is not likely to provide the right incentives for the country's policymakers. The implication for the design of IMF conditionality is that to induce higher effort to overcome the crisis, such conditionality should "bite" when the country's economic performance is low and should be weaker when the performance is better

Note that $e_{2 z^{L}}^{*}+e_{2 z^{H}}^{*}=-e_{2 I_{1}}^{*}$ holds, and that $e_{2 z^{L}}^{*}>\left|e_{2 z^{H}}^{*}\right|$ implies that, at the margin, the incentive effect of a higher repayment exceeds the disincentive effect. This is because the size of the incentive effect depends on the marginal utility at the lower income, $y_{2}^{L}+I_{1}-z^{L}$, whereas the disincentive effect depends on the marginal utility at the higher income, $y_{2}^{H}+I_{1}-z^{H}$.

Now, given the optimal strategy $e_{2}^{*}$ for a program country, we examine the optimal policy effort $e_{1}^{*}$ for a surveillance country. Again, assuming the optimal effort $e_{1}^{*}$ is strictly positive, the first order condition equates the marginal utility with the cost of the policy effort to prevent a crisis:

$$
\begin{aligned}
& \pi^{\prime}\left(e_{1}\right)\left[-u\left(y_{1}^{H}\right)+\pi\left(e_{2}^{*}\right) u\left(y_{2}^{L}+I_{1}-z^{L}\right)+\left[1-\pi\left(e_{2}^{*}\right)\right] u\left(y_{2}^{H}+I_{1}-z^{H}\right)-v\left(e_{2}^{*}\right)\right] \\
& -v^{\prime}\left(e_{1}\right)=0
\end{aligned}
$$

Equation (12) implicitly defines the optimal strategy $e_{1}^{*}$ in terms of $\left(y_{1}^{H}, y_{2}^{L}, y_{2}^{H}, I_{1}\right.$, $\left.z^{L}, z^{H} ; e_{2}^{*}\right)$. Using the envelope theorem, we derive the effect of each of the contract variables $\left\{I_{1}, z^{L}, z^{H}\right\}$ on the optimal policy effort $e_{1}^{*}$.

Proposition 3 The larger the first tranche, the smaller is $e_{1}^{*}: e_{1 I_{1}}^{*} \equiv\left(\frac{\partial e_{1}^{*}}{\partial I_{1}}\right)<0$; the larger the net repayment when the income is low, the higher is $e_{1}^{*}: e_{1 z^{L}}^{*} \equiv\left(\frac{\partial e_{1}^{*}}{\partial z^{L}}\right)>0$; the larger the net repayment when the income is high, the higher is $e_{1}^{*}: e_{1 z^{H}}^{*} \equiv$ $\left(\frac{\partial e_{1}^{*}}{\partial z^{H}}\right)>0$.

Proposition 3 shows that higher net repayments at the end, elicit a greater policy effort $e_{1}^{*}$ from member countries to prevent crises. Note that in contrast to the results for $e_{2}^{*}$, higher values of both $z^{L}$ and $z^{H}$ tend to induce a larger policy response $e_{1}^{*}$ from surveillance countries.

Two corollaries follow directly from Propositions 2 and 3.

Corollary 1 The larger the promised first tranche, the higher is the probability of a crisis situation developing, i.e. $\left(\frac{\partial \pi\left(e_{1}^{*}\right)}{\partial I_{1}}\right)>0$.

Corollary 2 The larger the first tranche, the higher is the probability of staying in a crisis, i.e. $\left(\frac{\partial \pi\left(e_{2}^{*}\right)}{\partial I_{1}}\right)>0$. 
These results suggest that, ceteris paribus, the IMF should minimize the size of the first tranche to provide member countries with the appropriate incentives, firstly, for preventing crises, and secondly, should they enter one, for expending the right amount of effort to get out of the crisis.

\subsection{The IMF's Choice of the Lending Contract}

Now, knowing a member country's optimal policy strategies $e_{1}^{*}$ and $e_{2}^{*}$, we examine the problem of designing the IMF's optimal contract. We classify a repayment scheme as compensatory if $z^{L *}<z^{H *}$, that is the net repayment by the country is lower in the low income state than in the high income state. If $z^{L *}>z^{H *}$ we will call the scheme non-compensatory.

The IMF's problem of choosing the optimal loan contract is specified as follows:

$$
\begin{array}{cl}
\max _{I_{1}, z^{L}, z^{H}} & E U_{I M F}\left(x, y_{1}^{H}, y_{2}^{H}, y_{2}^{L} ; I_{1}, z^{L}, z^{H}, e_{1}^{*}, e_{2}^{*}\right) \\
s . t & e_{1}^{*}=\underset{e_{1}}{\arg \max } E U_{S}\left(y_{1}^{H}, y_{1}^{L}, y_{2}^{H}, y_{2}^{L} ; I_{1}, z^{L}, z^{H}, e_{2}^{*}\right) \\
& e_{2}^{*}=\underset{e_{2}}{\arg \max } E U_{P}\left(y_{2}^{H}, y_{2}^{L} ; I_{1}, z^{L}, z^{H}\right) \\
E U_{S}\left(y_{1}^{H}, y_{1}^{L}, y_{2}^{H}, y_{2}^{L}, I_{1}, z^{L}, z^{H} ; e_{1}^{*}, e_{2}^{*}\right) \\
\geq \text { expected utility if country S stays outside the coinsurance } \\
\text { arrangement } \equiv\left[1-\pi\left(e_{1}^{* *}\right)\right] u\left(y_{1}^{H}\right)+\pi\left(e_{1}^{* *}\right) u\left(y_{1}^{L}\right)-v\left(e_{1}^{* *}\right) \\
E U_{P}\left(y_{2}^{H}, y_{2}^{L}, I_{1}, z^{L}, z^{H} ; e_{2}^{*}\right) \\
\geq \operatorname{expected~utility~for~a~crisis~country~P~that~does~not~use~the~IMF~} \\
\text { contract } \equiv u\left(y_{1}^{L}\right)
\end{array}
$$

The first two constraints are incentive compatibility constraints for a surveillance country and a program country. The last two constraints are participation constraints for a surveillance country and a program country. In order to set the participation constraints, we need to specify the expected utility of a country that stays outside the coinsurance arrangement and the expected utility of a member country in crisis that does not use the IMF contract . Note that once a country witnesses a crisis, it can either choose to be a program country and exert policy effort $e_{2}^{*}$ or remain in crisis and get $y_{1}^{L}$. From assumption 4 above, a surveillance country will choose to be a program country, and the participation constraint for a program country is satisfied. Before a country is hit by a crisis, the country can either accept the contract and become a surveillance country or reject the contract and stay outside the IMF. Again, from assumption 4 above, a country will prefer 
to be a member of the IMF and join the coinsurance arrangement. Note that $e_{1}^{* *}$ represents the policy effort of a country that decides not to become an IMF member. From assumption 4 above, we have

$$
\begin{aligned}
& E U_{P}\left(y_{2}^{H}, y_{2}^{L}, I_{1}, z^{L}, z^{H} ; e_{2}^{*}\right) \\
= & \left\{\pi\left(e_{2}^{*}\right) u\left(y_{2}^{L}+I_{1}-z^{L}\right)+\left[1-\pi\left(e_{2}^{*}\right)\right] u\left(y_{2}^{H}+I_{1}-z^{H}\right)-v\left(e_{2}^{*}\right)\right\}>u\left(y_{1}^{L}\right) .
\end{aligned}
$$

Thus, it is clear that $e_{1}^{* *}>e_{1}^{*}$, and as long as $u\left(y_{1}^{L}\right)$ is less than

$$
\left\{\left[v\left(e_{1}^{* *}\right)-v\left(e_{1}^{*}\right)\right]+u\left(y_{1}^{H}\right)\left[\pi\left(e_{1}^{* *}\right)-\pi\left(e_{1}^{*}\right)\right]+\pi\left(e_{1}^{*}\right) E U_{P}\left(y_{2}^{H}, y_{2}^{L}, I_{1}, z^{L}, z^{H} ; e_{2}^{*}\right)\right\} / \pi\left(e_{1}^{* *}\right),
$$

a country will participate in the loan contract the IMF proposes.

The IMF's contract design problem can be solved by backward induction. First, we solve the expected utility maximization problem for a program country given $\left(e_{1}, I_{1}, z^{L}, z^{H}\right)$. The solution yields the strategy $e_{2}^{*}=e_{2}^{*}\left(I_{1}, z^{L}, z^{H} ; e_{1}\right)$. Next, the expected utility maximization problem for a surveillance country is solved, given that it will adopt the strategy $e_{2}^{*}$, if it suffers a shock and becomes a program country. Finally, we find the optimal contract $\left(I_{1}^{*}, z^{L *}, z^{H *}\right)$ that the IMF should offer the countries in the coinsurance arrangement. Below, we will examine the IMF's problem of choosing the optimal contract, under each specification of its mandate.

\subsubsection{IMF Objective: Safeguarding Resources}

In this section, we assume that the IMF's objective function is given by (6). We denote the optimal contract for this objective of the IMF as $A^{*}=\left\{I_{1 A}^{*}, z_{A}^{L *}, z_{A}^{H *}\right\}$. The following proposition shows that if the IMF's sole concern is with safeguarding its resources, then it chooses a scheme requiring the country to pay it back in full.

Proposition 4 If the IMF's only objective is to safeguard its resources, then the optimal contract $A^{*}$ satisfies: $q \leq I_{1 A}^{*}=z_{A}^{L *}=z_{A}^{H *} \leq \min \left(y_{2}^{L}, n q\right)$.

In this case, the size of the loan is bounded above either by the country's output in the worst case scenariq ${ }^{18}$ or by the maximum possible amount of the initial tranche. As long as $I_{1 A}^{*}=z_{A}^{L *}=z_{A}^{H *}$, the IMF is not affected by the policy efforts of the country since in both, the high and low income states, the optimal level of the IMF's utility is $\hat{u}(x)$ Also, note that the problem has multiple solutions, and $I_{1 A}^{*}$ can take any value between $q$ and $\min \left(y_{2}^{L}, n q\right)$.

\footnotetext{
${ }^{18}$ Note that for simplicity we are assuming that the country's entire output is pledgeable to pay back the IMF's debt. The model can be easily modified to distinguish between tradeable and nontradebale output, with only the tradeable output being used to pay off the external debt.
} 
It is interesting to see the effect of the optimal contract on the policy effort levels of a surveillance country and a program country. First, from the special structure of the utility function of the IMF where the effort of a country only affects the probability of crisis, if a country will repay in full with certainty, the IMF does not care about policy effort. Then, the next question is whether the surveillance country or the program country will exert a positive level of effort or zero effort. Full repayments in both states imply that the contract variables $\left(I_{1}, z^{L}, z^{H}\right)$ do not appear in the expected utility of both the surveillance country and the program country. Thus, we can show that even under full repayment, the surveillance country and the program country generally make a positive level of effort.

\subsubsection{IMF Objective: Balancing Country Welfare and Safeguarding of Resources}

For the objective function given in (8), the first order conditions for the IMF's utility maximization with respect to the contract variables $\left\{I_{1}, z^{L}, z^{H}\right\}$ are:

$$
\begin{aligned}
0= & -\pi\left(e_{1}^{*}\right)\left\{\pi\left(e_{2}^{*}\right)\left[\hat{u}^{\prime}\left(x-I_{1}+z^{L}\right)-\theta u^{\prime}\left(y_{2}^{L}+I_{1}-z^{L}\right)\right]\right. \\
& \left.+\left[1-\pi\left(e_{2}^{*}\right)\right]\left[\hat{u}^{\prime}\left(x-I_{1}+z^{H}\right)-\theta u^{\prime}\left(y_{2}^{H}+I_{1}-z^{H}\right)\right]\right\} \\
& +\left(\frac{\partial e_{1}^{*}}{\partial I_{1}}\right) \pi^{\prime}\left(e_{1}^{*}\right)\left\{\pi\left(e_{2}^{*}\right) \hat{u}\left(x-I_{1}+z^{L}\right)+\left[1-\pi\left(e_{2}^{*}\right)\right] \hat{u}\left(x-I_{1}+z^{H}\right)-\hat{u}(x)\right\} \\
& +\left(\frac{\partial e_{2}^{*}}{\partial I_{1}}\right) \pi\left(e_{1}^{*}\right) \pi^{\prime}\left(e_{2}^{*}\right)\left[\hat{u}\left(x-I_{1}+z^{L}\right)-\hat{u}\left(x-I_{1}+z^{H}\right)\right]
\end{aligned}
$$

$$
\begin{aligned}
0= & \pi\left(e_{1}^{*}\right) \pi\left(e_{2}^{*}\right)\left[\hat{u}^{\prime}\left(x-I_{1}+z^{L}\right)-\theta u^{\prime}\left(y_{2}^{L}+I_{1}-z^{L}\right)\right] \\
& +\left(\frac{\partial e_{1}^{*}}{\partial z^{L}}\right) \pi^{\prime}\left(e_{1}^{*}\right)\left\{\pi\left(e_{2}^{*}\right) \hat{u}\left(x-I_{1}+z^{L}\right)+\left[1-\pi\left(e_{2}^{*}\right)\right] \hat{u}\left(x-I_{1}+z^{H}\right)-\hat{u}(x)\right\} \\
& +\left(\frac{\partial e_{2}^{*}}{\partial z^{L}}\right) \pi\left(e_{1}^{*}\right) \pi^{\prime}\left(e_{2}^{*}\right)\left[\hat{u}\left(x-I_{1}+z^{L}\right)-\hat{u}\left(x-I_{1}+z^{H}\right)\right]
\end{aligned}
$$

$$
\begin{aligned}
0= & \pi\left(e_{1}^{*}\right)\left[1-\pi\left(e_{2}^{*}\right)\right]\left[\hat{u}^{\prime}\left(x-I_{1}+z^{H}\right)-\theta u^{\prime}\left(y_{2}^{H}+I_{1}-z^{H}\right)\right] \\
& +\left(\frac{\partial e_{1}^{*}}{\partial z^{H}}\right) \pi^{\prime}\left(e_{1}^{*}\right)\left\{\pi\left(e_{2}^{*}\right) \hat{u}\left(x-I_{1}+z^{L}\right)+\left[1-\pi\left(e_{2}^{*}\right)\right] \hat{u}\left(x-I_{1}+z^{H}\right)-\hat{u}(x)\right\} \\
& +\left(\frac{\partial e_{2}^{*}}{\partial z^{H}}\right) \pi\left(e_{1}^{*}\right) \pi^{\prime}\left(e_{2}^{*}\right)\left[\hat{u}\left(x-I_{1}+z^{L}\right)-\hat{u}\left(x-I_{1}+z^{H}\right)\right]
\end{aligned}
$$


Equations (13), (14) and (15) are used to solve for the optimal contract $B^{*}=$ $\left\{I_{1 B}^{*}, z_{B}^{L *}, z_{B}^{H *}\right\}$. In this general model, depending on the values of the parameters, the optimal repayment can be either compensatory or noncompensatory. The following proposition shows that, depending on $x$, the amount of resources available to the IMF, and $\theta$, the extent of concern the IMF has for the country's utility, the optimal repayment scheme can vary from zero repayment in both the high and low income states in the second period to full repayment in both states.

Proposition 5 If the IMF's objective function is given by (8), then the following holds: (i) If $x$ is small, say, $x \ll y_{2}^{L}$, and $\theta \gg 0$, then the IMF's optimal contract $B^{*}=\left\{I_{1 B}^{*}, z_{B}^{L *}, z_{B}^{H *}\right\}$ satisfies $I_{1 B}^{*}=z_{B}^{H *}=z_{B}^{L *}=q$. (ii) If $x$ is large, say, $x \gg y_{2}^{H}$, and $\theta \gg 0$, then the IMF's optimal contract $B^{*}=\left\{I_{1 B}^{*}, z_{B}^{L *}, z_{B}^{H *}\right\}$ satisfies $z_{B}^{L *}=$ $z_{B}^{H *}=0$ and $I_{1 B}^{*}=\min (n q, x)=n q$.

With explicit concern for the country's utility, the IMF faces a trade-off between safeguarding its resources and enhancing a country's utility. If $\theta$ is close to 0 , then, the problem reduces to that solved in the previous section; the IMF focuses on safeguarding resources and the optimal repayment scheme requires full repayment. On the other hand, if $\theta$ is large, the IMF puts more emphasis on a country's utility. Thus, the IMF lends as much as possible to the country, and even no repayment by the country may be optimal.

Now, the amount of resources available to the IMF also matters. The intuition is straightforward. Suppose that the IMF's resources are small compared to the size of the country. Then, given the concavity of the utility function, the IMF's utility increases by a large amount when it receives repayment from the country, while the country's utility decreases by a relatively small amount. Thus, the IMF's utility increases overall by demanding higher repayment. Moreover, the higher repayment increases the policy effort, which will generally increase the utility of the IMF. Therefore, it is optimal for the IMF to get as large a repayment as possible.

Suppose, on the other hand, the resources of the IMF are "large" compared to the income of a recipient country. Then, the IMF's utility decreases by a small amount when it gives up receiving payment from the program country. On the other hand, the country's utility increases substantially due to the higher second-period income as a result of the IMF's net transfer. Since the IMF's utility is in turn affected by that of the borrowing country, depending on the value of $\theta$, some degree of debt forgiveness may be optimal 19 Note that for the IMF's utility to increase overall,

\footnotetext{
${ }^{19}$ It is important to point out that in our framework, contracts have only a single dimension- the size of the loan - and hence the only incentivizing device is "debt forgiveness." Introducing richer
} 
the utility increase from caring about the country has to be larger than the decrease in the IMF's utility stemming from the lower policy effort due to debt forgiveness.

An interesting question is whether the IMF's mandate has any implications for the policy effort of countries. Is it the case that an IMF which only cares about safeguarding its resources induces higher policy effort than an IMF which also cares about country welfare? Proposition 6 shows that it is not necessarily so.

Proposition 6 Assume that the optimal policy actions, $e_{1}^{*}$ and $e_{2}^{*}$, are interior solutions. Then, if

$$
u\left(y_{2}^{H}+I_{1 A}^{*}-z_{A}^{H *}\right)-u\left(y_{2}^{L}+I_{1 A}^{*}-z_{A}^{L *}\right)>(<) u\left(y_{2}^{H}+I_{1 B}^{*}-z_{B}^{H *}\right)-u\left(y_{2}^{L}+I_{1 B}^{*}-z_{B}^{L *}\right),
$$

the optimal policy actions satisfy $e_{2}^{* A}>(<) e_{2}^{* B}$. Further, if

$$
\begin{gathered}
E U_{P}^{* A} \equiv \pi\left(e_{2}^{* A}\right) u\left(y_{2}^{L}+I_{1 A}^{*}-z_{A}^{L *}\right)+\left[1-\pi\left(e_{2}^{* A}\right)\right] u\left(y_{2}^{H}+I_{1 A}^{*}-z_{A}^{H *}\right)-v\left(e_{2}^{* A}\right)> \\
(<) E U_{P}^{* B} \equiv \pi\left(e_{2}^{* B}\right) u\left(y_{2}^{L}+I_{1 B}^{*}-z_{B}^{L *}\right)+\left[1-\pi\left(e_{2}^{* B}\right)\right] u\left(y_{2}^{H}+I_{1 B}^{*}-z_{B}^{H *}\right)-v\left(e_{2}^{* B}\right),
\end{gathered}
$$

we have $e_{1}^{* A}<(>) e_{1}^{* B}$.

The first part of the proposition states that, if the difference of the utility levels corresponding to the good and the bad outcomes gets smaller when the IMF starts to consider country welfare, then the program country exerts less effort to overcome the crisis. The second part states that, if the expected utility of the program country becomes larger when the IMF objective changes from only safeguarding resources to considering both safeguarding of resources and country welfare, then the surveillance country exerts less effort to avoid the crisis.

Consider the following examples based on three different sets of optimal loan contracts.

Example $1 A^{*} \equiv\left\{I_{1 A}^{*}=z_{A}^{L *}=z_{A}^{H *}\right\}$ and $B^{*} \equiv\left\{z_{B}^{H *}<z_{B}^{L *}=I_{1 B}^{*}\right\}$.

This is a case where the repayment of the IMF is non-compensatory. Now $u\left(y_{2}^{H}\right)-u\left(y_{2}^{L}\right)<u\left(y_{2}^{H}+I_{1 B}^{*}-z_{B}^{H *}\right)-u\left(y_{2}^{L}\right)$. Thus, $e_{2}^{* A}<e_{2}^{* B}$. The intuition is that a subsidy in the good state increases the level of effort to avoid the bad outcome. In this case, depending on the relative size of $E U_{P}^{* A}$ and $E U_{P}^{* B}$, we can get either $e_{1}^{* A}>e_{1}^{* B}$ or $e_{1}^{* A}<e_{1}^{* B}$.

Example $2 A^{*} \equiv\left\{I_{1 A}^{*}=z_{A}^{L *}=z_{A}^{H *}\right\}$ and $B^{*} \equiv\left\{z_{B}^{L *}<z_{B}^{H *}=I_{1 B}^{*}\right\}$.

contracts with more dimensions, such as conditionality, would give the IMF more instruments to achieve its objectives without having to resort to "debt forgiveness."

www.economics-ejournal.org 
This is a case when the repayment scheme of the IMF is compensatory. Now $u\left(y_{2}^{H}\right)-u\left(y_{2}^{L}\right)>u\left(y_{2}^{H}\right)-u\left(y_{2}^{L}+I_{1 B}^{*}-z_{B}^{L *}\right)$. Thus, $e_{2}^{* A}>e_{2}^{* B}$. Here, the forgiveness in the bad state lowers the level of effort to avoid the bad outcome. Again in this case, depending on the relative size of $E U_{P}^{* A}$ and $E U_{P}^{* B}$, we can get either $e_{1}^{* A}>e_{1}^{* B}$ or $e_{1}^{* A}<e_{1}^{* B}$.

Example $3 A^{*} \equiv\left\{I_{1 A}^{*}=z_{A}^{L *}=z_{A}^{H *}\right\}$ and $B^{*} \equiv\left\{z_{B}^{L *}=z_{B}^{H *}=0, I_{1 B}^{*}=n q\right\}$.

This is the case where the resources of the IMF are very large, as in Proposition 7 (ii). Due to the strict concavity of the utility function, $u\left(y_{2}^{H}\right)-u\left(y_{2}^{L}\right)>u\left(y_{2}^{H}+\right.$ $n q)-u\left(y_{2}^{L}+n q\right)$. Thus, $e_{2}^{* A}>e_{2}^{* B}$. This result shows that when a country receives a large subsidy or debt forgiveness irrespective of whether it emerges from a crisis or not, it exerts less effort to sort through its problems. Also, as long as $n q \geq y_{2}^{H}-y_{2}^{L}$, we have

$$
\begin{aligned}
\pi\left(e_{2}^{* A}\right) u\left(y_{2}^{L}\right)+\left[1-\pi\left(e_{2}^{* A}\right)\right] u\left(y_{2}^{H}\right)-v\left(e_{2}^{* A}\right) \\
\quad<\pi\left(e_{2}^{* B}\right) u\left(y_{2}^{L}+n q\right)+\left[1-\pi\left(e_{2}^{* B}\right)\right] u\left(y_{2}^{H}+n q\right)-v\left(e_{2}^{* B}\right)
\end{aligned}
$$

and thus $e_{1}^{* A}>e_{1}^{* B}$ holds.

Thus, Proposition 6 shows that mandating the IMF to care about country welfare in addition to safeguarding its resources, does not necessarily imply that member countries will spend less effort in preventing imbalances from arising, or if problems should arise, spend less effort for their resolution.

\subsection{Timing of Loan Contracts}

Throughout this subsection, we will assume that the IMF cares both about safeguarding its resources and the borrowing country's utility. As pointed out in Khan and Sharma (2003), the IMF, given such a mandate, faces the Samaritan's dilemma. This dilemma arises whenever the availability or granting of assistance leads to making it more likely that the conditions that evoke such aid will hold. Faced with underperformance and a weak economy, countries know that the IMF will provide assistance because it is concerned with the borrowing country's welfare. The knowledge that the IMF will come to their assistance if they run into trouble, may make countries to be lax in correcting policy imbalances and exert less effort for crisis prevention. Under these conditions, should the IMF precommit to a contingent contract before a country experiences a crisis, or should it formulate a loan contract after a country is in crisis?

We consider three timings for the IMF loan contract: 
Case 1 Ex-ante contract.

The IMF precommits to a contingent loan contract $B=\left\{I_{1 B}, z_{B}^{L}, z_{B}^{H}\right\}$ before the country chooses policy effort $e_{1}$. This case was analyzed in the previous section.

Case 2 Ex-post contract.

The IMF chooses contract $C=\left\{I_{1 C}, z_{C}^{L}, z_{C}^{H}\right\}$ after $e_{1}$ has been chosen (and the country enters a crisis) but before the country chooses $e_{2}$.

Case 3 A variation of Ex-post contract.

The IMF chooses contract $D=\left\{I_{1 D}, z_{D}^{L}, z_{D}^{H}\right\}$, where the IMF chooses $I_{1 D}$ after $e_{1}$ has been chosen and $\left(z_{D}^{L}, z_{D}^{H}\right)$ after the country chooses $e_{2}$.

For Case 2, the IMF's expected utility function can be written as:

$$
\begin{aligned}
E U_{I M F}= & \pi\left(e_{2}\right)\left[\hat{u}\left(x-I_{1}+z^{L}\right)+\theta u\left(y_{2}^{L}+I_{1}-z^{L}\right)\right] \\
& +\left[1-\pi\left(e_{2}\right)\right]\left[\hat{u}\left(x-I_{1}+z^{H}\right)+\theta u\left(y_{2}^{H}+I_{1}-z^{H}\right)\right]-\theta v\left(e_{2}\right)
\end{aligned}
$$

Note that (17) differs from the expected utility function in the previous section where the IMF could precommit to a contract before a crisis occurred. The optimal contract $C^{*}$ is obtained from the following first-order conditions:

$$
\begin{aligned}
0= & -\pi\left(e_{2}\right)\left[\hat{u}^{\prime}\left(x-I_{1}+z^{L}\right)-\theta u^{\prime}\left(y_{2}^{L}+I_{1}-z^{L}\right)\right] \\
& -\left[1-\pi\left(e_{2}\right)\right]\left[\hat{u}^{\prime}\left(x-I_{1}+z^{H}\right)-\theta u^{\prime}\left(y_{2}^{H}+I_{1}-z^{H}\right)\right] \\
& +e_{2 I_{1}}\left\{\pi^{\prime}\left(e_{2}\right)\left[\hat{u}\left(x-I_{1}+z^{L}\right)-\hat{u}\left(x-I_{1}+z^{H}\right)\right]\right\} \\
& \\
0= & \pi\left(e_{2}\right)\left[\hat{u}^{\prime}\left(x-I_{1}+z^{L}\right)-\theta u^{\prime}\left(y_{2}^{L}+I_{1}-z^{L}\right)\right] \\
& +e_{2 z^{L}}\left\{\pi^{\prime}\left(e_{2}\right)\left[\hat{u}\left(x-I_{1}+z^{L}\right)-\hat{u}\left(x-I_{1}+z^{H}\right)\right]\right\} \\
& \\
& \\
0= & {\left[1-\pi\left(e_{2}\right)\right]\left[\hat{u}^{\prime}\left(x-I_{1}+z^{H}\right)-\theta u^{\prime}\left(y_{2}^{H}+I_{1}-z^{H}\right)\right] } \\
& +e_{2 z^{H}}\left\{\pi^{\prime}\left(e_{2}\right)\left[\hat{u}\left(x-I_{1}+z^{L}\right)-\hat{u}\left(x-I_{1}+z^{H}\right)\right]\right\}
\end{aligned}
$$

The IMF offers contract $C^{*}=\left\{I_{1 C}^{*}, z_{C}^{L *}, z_{C}^{H *}\right\}$ to a country after it has entered a crisis. Also, since the IMF's objective is to balance the safeguarding of its resources while being concerned about country welfare, we expect the optimal contract to be compensatory. The following proposition formalizes this intuition. 
Proposition 7 If the IMF cares about both safeguarding its resources and country welfare, under an ex-post contract, the repayment scheme is compensatory, with the program country repaying more if the country recovers from the crisis and less if it does not recover.

Now let's consider Case 3. Note that in this case there is no remaining uncertainty, and an IMF that cares about country welfare finds it optimal to provide full insurance to a country. Moreover, the repayment scheme is compensatory for strictly positive values of $\theta$, i.e., $z_{D}^{H *}>z_{D}^{L *}$.

Next we compare, how the three contracts $B, C$, and $D$ affect a country's policy effort and the extent to which the IMF provides debt forgiveness. To this end, define $T^{H} \equiv I_{1}-z^{H}$ as the net transfer (or the amount of debt forgiveness) to the program country if it recovers from the crisis and $T^{L} \equiv I_{1}-z^{L}$ as the net transfer if the country does not emerge from the crisis.

The following lemma shows that, given a lower bound on the probability of remaining in a crisis (once it occurs), the effect of $T^{L}$ on the policy effort to avoid a crisis is greater than that of $T^{H}$.

Lemma 2 If $\pi\left(e_{2}\right) \geq \frac{1}{2}, \forall e_{2}$, then $\left|\frac{\partial e_{1}^{*}}{\partial T^{L}}\right|>\left|\frac{\partial e_{1}^{*}}{\partial T^{H}}\right|$.

The above lemma is used in proving the following proposition on crisis prevention and recovery effort and net transfers under the three contracts.

Proposition 8 Assume that :

(1) The expected utility function of the IMF, EU IMF, is twice continuously differentiable with respect to $T^{H}$ and $T^{L}$.

(2) $\left\{I_{1 B}, z_{B}^{L}, z_{B}^{H}\right\}$ and $\left\{I_{1 C}, z_{C}^{L}, z_{C}^{H}\right\}$ are interior solutions.

(3) $\frac{\partial^{2} E U_{I M F}}{\partial\left(T^{i}\right)^{2}}<0, \frac{\partial^{2} E U_{I M F}}{\partial T^{i} \partial T^{j}}>0$, and $\left|\frac{\partial^{2} E U_{I M F}}{\partial\left(T^{i}\right)^{2}}\right|>\frac{\partial^{2} E U_{I M F}}{\partial T^{i} \partial T^{j}}, i, j=H, L, i \neq j$.

(4) $\frac{\partial^{2} E U_{I M F}}{\partial\left(T^{H}\right)^{2}} \approx \frac{\partial^{2} E U_{I M F}}{\partial\left(T^{L}\right)^{2}}$.

(5) $E U_{P}\left(T_{B}^{H *}, T_{B}^{L *}, e_{2}^{* B}\right)<E U_{P}\left(T_{C}^{H *}, T_{C}^{L *}, e_{2}^{* C}\right)<E U_{P}\left(T_{D}^{H *}, T_{D}^{L *}, e_{2}^{* D}\right)$.

Then, under assumptions (1)-(4), the three optimal contracts $B^{*}, C^{*}$, and $D^{*}$ satisfy:

(a) $e_{2}^{* B}>e_{2}^{* C}>e_{2}^{* D}$;

(b) $T_{D}^{L *}>T_{C}^{L *}>T_{B}^{L *} ; T_{C}^{H *}>T_{D}^{H *}$ and $T_{C}^{H *}>T_{B}^{H *}$.

Further, under assumptions (1)-(5), the optimal policy efforts elicited by the contracts satisfy

(c) $e_{1}^{* B}>e_{1}^{* C}>e_{1}^{* D}$. 
Proposition 8 shows that when the policy efforts of the country to prevent and overcome a crisis are not fully observed by the IMF, under some conditions a precommitment to a lending contract, $B^{*}$, elicits a greater amount of crisis prevention effort and crisis-overcoming effort from countries, than the offering of the contract $C^{*}$ after the crisis has occurred. It also shows that some commitment is better than none at all, since contract $C^{*}$ induces higher efforts than contract $D^{*}$.

In terms of debt forgiveness, precommitment leads to the least amount of forgiveness if the program country cannot get out of the crisis. On the other hand, if the program country is successful in getting out of the crisis, contract $C^{*}$ provides the largest amount of debt forgiveness to the program country. The intuition for this is that under contract $D^{*}$ the IMF decides on the amount of forgiveness after it observes whether the program country is successful in getting out of the crisis or not. Once the IMF knows that the country is out of the crisis, as it does under contract $D^{*}$, it is optimal for the IMF to reduce the amount of debt forgiveness compared to the situation under contract $C^{*}$, where the terms are decided before such information is available to the IMF.

From Propositions 7 and 8, Corollary 3 follows immediately.

Corollary $3 T_{D}^{L *}>T_{C}^{L *}>T_{C}^{H *}>T_{D}^{H *}$.

It implies that, compared to contract $D^{*}$, under contract $C^{*}$ debt forgiveness by the IMF is lower when the program country remains in crisis, and higher when it is able to get out of a crisis.

\subsection{Precommitment and Time-Consistency}

The idea of precommitment entails an ex-ante agreement on the contingent loan contract between the IMF and a member country. But commitment to an ex ante contract (that is a contract agreed to before problems arise) suffers from the timeinconsistency problem (Kydland and Prescott (1977)). If the country knows that ex post (that is, after a country's situation deteriorates) the IMF will be willing to renegotiate the contract, ex ante country ownership of the contract is less likely ${ }^{20}$ Some observers have questioned the credibility of conditionalities attached to IMF lending (Stone (2004), Eldar (2006), Bird (2007)).

The problem of time inconsistency arises even in an environment of complete and perfect information. For an altruistic lender, there is the additional dimension that the borrower knows that it will be optimal for the lender to renege on penalties agreed to ex ante - the economics of fait accompli (Bernheim and Stark (1988),

\footnotetext{
${ }^{20}$ See, Drazen and Fischer (1997) and Khan and Sharma (2003).
} 
Lindbeck and Weibull (1988)). The presence of informational asymmetries exacerbates the problem even further - the lender cannot easily verify the policy effort and hence cannot contract on such effort; it also changes the prescription for dealing with the dilemmas posed by altruism and sequential decision making. This paper shows that, for an altruistic lender facing information asymmetries, it may be best to precommit to an ex ante loan contract rather than define the contract ex post ${ }^{21}$

Suppose, for the sake of simplicity, that the menu of contracts consists of two contracts - the ex ante contract $B^{*}$ and the ex post contract $C^{*}$ defined in the previous section. Then, Proposition 10 shows that the IMF will choose contract $B^{*}$ before a crisis occurs. Now consider what happens when a country runs into trouble. Once $e_{1}^{*}$ is chosen and the country falls into a crisis, the optimal contract for the IMF is $C^{*}$. Since $B^{*}$ and $C^{*}$ need not be the same, the IMF has an incentive to change its contract once the country descends into a crisis. The intuition is as follows: When the IMF offers contract $B^{*}$ to a surveillance country, its objective is to provide the country with the incentive to both, prevent a crisis, and should a crisis occur, to expend effort to change course. Thus, the contract is designed to achieve these goals, while giving consideration to the country's welfare. However, once a crisis erupts, the IMF's focus is to encourage the country to exert adequate effort to get out of the crisis. Under the new circumstances, a different contract, $C^{*}$, is optimal. Hence, the IMF is willing to change the contract over time ${ }^{22}$

Now consider the problem the country faces over time. A country in crisis may prefer the contract $C^{*}$ to going through with $B^{*}$ which may have been preferred before the crisis was encountered. If the program country obtains higher expected utility from $C^{*}$, renegotiation by the IMF and the country may make both of them better off. Again, time inconsistency stems from the fact that the IMF may prefer

\footnotetext{
${ }^{21}$ Aside from altruism, the IMF faces additional hurdles in its operation compared to a traditional lender-of-last-resort (Tirole (2002) and Khan and Sharma (2003)). First, lending takes place on the promise that country authorities will implement policies to rectify imbalances, and it is difficult, if not impossible, to establish the value of such "collateral." Second, the information asymmetries and hence the moral hazard is likely to be more pronounced. The IMF faces what in agency theory is called "moral hazard in teams"—-while program negotiations are conducted with certain representatives of the government (central bank, finance ministry), the success of the program depends on the acceptance and effort of many other stakeholders in society (other ministries, political parties, trade unions, professional associations, civic groups, NGOs) (Holmström (1982)). Third, the enforcement mechanism for ensuring that borrowing countries live up to their obligations essentially amounts to some combination of moral suasion, maintenance of the borrower's reputation, peer pressure, and the threat of being shut out of international capital markets.

${ }^{22}$ To go further, once the country chooses $e_{2}^{*}$, then depending on whether the country gets out of the crisis or not, the IMF may find that yet another contract $D^{*}$, different from $C^{*}$, is optimal.
} 
to change its contract as the situation changes.

This begs the question whether such contract renegotiation should be permitted and whether it is in the global interest 23 The community of nations may well prefer that contract $B^{*}$ be offered and enforced, since it leads to higher country effort to prevent problems from emerging, higher country effort to escape crises, and a smaller transfer of resources by the IMF.

The model presented in the paper has analyzed a single interaction between the IMF and a country. In a setting where there is repeated lending, it may be in the IMF's interest to precommit to a contract such as $B^{*}$, and build a reputation for enforcing the contract. Over time, this could lead to the emergence of an international norm under which the IMF offers and enforces a "standard" contract. Renegotiation would be allowed only under exceptional circumstances, for example, when it is perceived that the country in crisis poses a systemic threat to the world economy. The paper does not explicitly model the time consistency issue. To address this issue, it would be interesting to formulate a fully dynamic model, and investigate the challenges posed by commitment and renegotiation more rigorously.

\section{Concluding Remarks}

This paper argues that in the presence of information asymmetries and given the mandate of the IMF to safeguard its resources and care about the welfare of borrowing countries, the IMF should precommit to a lending contract. ${ }^{24}$ Such a precommitment elicits the right policy effort from countries to prevent crises and to recover from them. However, a contract agreed to before a crisis erupts is subject to time-inconsistency problems, since the Fund and the country may both find it in their interest to renegotiate the ex ante contract, once the country enters into a crisis. Hence, a country, knowing that the IMF will renegotiate the contract if it

\footnotetext{
${ }^{23}$ In the context of our model, the parameter $\theta$ can be given a different interpretation to capture the "too-big-to-fail" issue. One could think of $\theta$ as the importance the IMF attaches to a country, with the size of $\theta$ depending on the consequences a crisis in that country would have for the international financial system. Large systemically important countries would be assigned larger $\theta \mathrm{s}$ and for these countries the time inconsistency problem would be more severe. Knowing this, such countries are more likely to be successful in renegotiating their contracts and obtaining weaker programs.

${ }^{24}$ Note that precommitment to a lending contract for all members is quite different from prequalifying members for access as was done for the IMF's Contingent Credit Line (CCL) facility. The CCL facility had to contend with the concern that signing up for it may be taken as a signal of weakness, and that ineligibility at a future date may have a negative fallout.
} 
experiences a crisis, is less likely to own the program ex ante and give credence to statements that additional funds or concessions will not be made.

Our results can be taken as a defense of existing IMF procedures that define annual and overall access limits to resources for program countries. Limits on IMF lending and rewards for good housekeeping were favored by the independent task force sponsored by the Council on Foreign Relations (1999). The Meltzer Commission also suggested that the IMF should provide resources up to specific limits, but only to prequalified countries and at penalty interest rates.25 A key objection to the prequalification requirement was that it would exclude a large number of member countries, and hence would be fundamentally inconsistent with the rights of all members to access IMF resources under the Articles of Agreement. ${ }^{26}$

In many recent programs, normal IMF access limits (100 percent of a country's quota annually and 300 percent of quota cumulatively) have been breached by wide margins. This paper does not address the difficult question of how large the IMF should be for effectively performing its role as a coinsurance arrangement and crisis manager. In an era of capital mobility, country quota levels and access limits may need to be recalibrated. Among other things, the size of the IMF will depend on the size distribution and health of member countries; the extent to which countries have access to private capital markets; the volatility of international finance (or more generally the real hazards that have to be dealt with); the effectiveness of IMF surveillance; and the catalyzing role of IMF lending ${ }^{27}$ And, since the IMF as a lender of last resort plays an important role in preventing liquidity runs, access limits and conditionality should be set to strike a balance between creating moral hazard and avoiding runs.

The design of an ex ante loan contract involves specifying the interest rate charged, and the maturity of the loan. If the IMF is limited in its ability to charge different credit spreads across countries, to safeguard its resources the IMF could still attach different policy conditionality to the loan contract depending on a country's characteristics and the imbalances the country is facing. Countries could be allowed to choose loans from a predefined set of maturities, and the rate of charge

\footnotetext{
${ }^{25}$ See, Meltzer et al. (2000). Prequalification was to be based on four factors: (i) free entry of foreign financial institutions; (ii) regular and timely publication of the maturity structure of sovereign and government guaranteed debt; (iii) adequate capitalization of commercial banks; and (iv) a fiscal requirement.

${ }^{26}$ For more on the debate see Eichengreen (1999), Goldstein (2000), and U.S. Treasury (2000).

${ }^{27}$ For a discussion on the nature and size of the IMF, see Jeanne and Wyplosz (2001). For the catalyzing role of IMF lending see the recent survey by Hovaguimian (2003) and the references therein.
} 
could increase with maturity to create an incentive for countries to deal with the situation quickly and repay the IMF.

An IMF commitment to a loan contract that ex ante stipulates access limits, size of tranches, interest rates, and maturities may have other advantages. First, it would make it easier for countries to decide how much self-insurance they should buy. ${ }^{28}$ Second, it would make clear to private creditors the extent of IMF resources a country could tap if it ran into liquidity problems, and hence contribute to limiting creditor moral hazard. As a country accumulates debt in international and domestic markets, private lenders, knowing the limits of IMF support, may be quicker to react to signs of emerging imbalances than they would if the extent of IMF support was not specified (Haldane and Kruger (2001)). Third, an international coinsurance arrangement among countries is essentially a self-regulatory club. It can be argued that when members do not live up to their obligations, like other self-regulated organizations, the IMF may not impose the discipline the international tax payers would deem appropriate. Hence, an international norm that restricts the access of countries to IMF resources through prespecified limits and terms, except when there is a systemic threat, may be a useful commitment mechanism.

\footnotetext{
${ }^{28}$ For a discussion of foreign exchange reserve accumulation and self-insurance, see Lee (2004).
} 


\section{Appendix: Proofs}

\section{Proof for Lemma 1.}

$$
\begin{aligned}
E\left(U_{i}\right) & =\left(1-\pi_{i}\right)\left(1-\pi_{j}\right) u\left(y_{i}\right)+\left(1-\pi_{i}\right) \pi_{j} u\left(y_{i}-\beta\right)+\pi_{i}\left(1-\pi_{j}\right) u\left(y_{i}-\delta+\beta\right) \\
& +\pi_{i} \pi_{j} u\left(y_{i}-\delta\right)-v\left(e_{i}\right) \\
& +\lambda_{i}\left\{\left(1-\pi_{j}\right)\left(1-\pi_{i}\right) u\left(y_{j}\right)+\left(1-\pi_{j}\right) \pi_{i} u\left(y_{j}-\beta\right)+\pi_{j}\left(1-\pi_{i}\right) u\left(y_{j}-\delta+\beta\right)\right. \\
& \left.+\pi_{j} \pi_{i} u\left(y_{j}-\delta\right)-v\left(e_{j}\right)\right\}
\end{aligned}
$$

The first-order condition with respect to $e_{i}$ is

$$
\begin{aligned}
& -\pi_{i}^{\prime}\left(1-\pi_{j}\right)\left[u\left(y_{i}\right)+\lambda_{i} u\left(y_{j}\right)\right]-\pi_{i}^{\prime} \pi_{j}\left[u\left(y_{i}-\beta\right)+\lambda_{i} u\left(y_{j}-\delta+\beta\right)\right] \\
& +\pi_{i}^{\prime}\left(1-\pi_{j}\right)\left[u\left(y_{i}-\delta+\beta\right)+\lambda_{i} u\left(y_{j}-\beta\right)\right]+\pi_{i}^{\prime} \pi_{j}\left[u\left(y_{i}-\delta\right)+\lambda_{i} u\left(y_{j}-\delta\right)\right]-v^{\prime}\left(e_{i}\right)=0 .
\end{aligned}
$$

By symmetry, we can use $e_{i}^{*}=e_{j}^{*}=e^{*}(\beta)$ and $y_{i}=y_{j}=y$. From (i),

$$
\begin{aligned}
& \pi_{i}^{\prime}\left\{\pi_{j}\left[u^{\prime}(y-\beta)-\lambda u^{\prime}(y-\delta+\beta)\right]+\left(1-\pi_{j}\right)\left[u^{\prime}(y-\delta+\beta)-\lambda u^{\prime}(y-\beta)\right]\right\} d \beta+\Delta d e_{i}^{*}=0, \\
& \text { where } \Delta \equiv \frac{\partial^{2} E\left(U_{i}\right)}{\left(\partial e_{i}\right)^{2}}<0 \text { for all } \lambda \geq 0 \text {. Thus, } \\
& \frac{\partial e_{i}^{*}}{\partial \beta}=-\frac{\pi_{i}^{\prime}}{\Delta}\left\{\pi_{j}\left[u^{\prime}(y-\beta)-\lambda u^{\prime}(y-\delta+\beta)\right]+\left(1-\pi_{j}\right)\left[u^{\prime}(y-\delta+\beta)-\lambda u^{\prime}(y-\beta)\right]\right\} .
\end{aligned}
$$

We know from the first order condition with respect to $\beta$ that, in the symmetric equilibrium, $\beta^{*}=\delta / 2$ should hold to make the marginal utilities equal. Plugging this into (ii), as $\lambda \rightarrow 1$, we get $\frac{\partial e_{i}^{*}}{\partial \beta} \rightarrow 0$. Alternatively, as $\lambda \rightarrow 1$, and the countries tend to attach the same relative weight to each others utility. Therefore, their marginal utilities in each state will tend to equality and the term $\left\{\pi_{j}\left[u^{\prime}(y-\beta)-\lambda u^{\prime}(y-\delta+\beta)\right]+\left(1-\pi_{j}\right)\left[u^{\prime}(y-\delta+\beta)-\lambda u^{\prime}(y-\beta)\right]\right\}$ will converge to zero.

Q.E.D. 


\section{Proof for Proposition 1.}

Without loss of generality, we assume that $y_{i}>y_{j}$. Then, proceeding in the same way as in the proof of Lemma 1 except that $y_{i}>y_{j}$ and $e_{i}^{*} \neq e_{j}^{*}$, we get the following equalities for countries $i$ and $j$ :

$$
\begin{aligned}
& \frac{\partial e_{i}^{*}}{\partial \beta}=-\frac{\pi_{i}^{\prime}}{\Delta}\left\{\pi_{j}\left[u^{\prime}\left(y_{i}-\beta\right)-\lambda u^{\prime}\left(y_{j}-\delta+\beta\right)\right]+\left(1-\pi_{j}\right)\left[u^{\prime}\left(y_{i}-\delta+\beta\right)-\lambda u^{\prime}\left(y_{j}-\beta\right)\right]\right\} \\
& \frac{\partial e_{j}^{*}}{\partial \beta}=-\frac{\pi_{j}^{\prime}}{\Delta}\left\{\pi_{i}\left[u^{\prime}\left(y_{j}-\beta\right)-\lambda u^{\prime}\left(y_{i}-\delta+\beta\right)\right]+\left(1-\pi_{i}\right)\left[u^{\prime}\left(y_{j}-\delta+\beta\right)-\lambda u^{\prime}\left(y_{i}-\beta\right)\right]\right\}
\end{aligned}
$$

As $\lambda \rightarrow 1$, the marginal utilities of country $i$ and country $j$ can be equal in both states at the same time, if and only if, the following two equations hold at the same time:

$$
\begin{aligned}
& \pi_{j}\left(e_{j}^{*}\right)=\frac{u^{\prime}\left(y_{j}-\beta\right)-u^{\prime}\left(y_{i}-\delta+\beta\right)}{u^{\prime}\left(y_{i}-\beta\right)-u^{\prime}\left(y_{i}-\delta+\beta\right)+u^{\prime}\left(y_{j}-\beta\right)-u^{\prime}\left(y_{j}-\delta+\beta\right)} \\
& \pi_{i}\left(e_{i}^{*}\right)=\frac{u^{\prime}\left(y_{i}-\beta\right)-u^{\prime}\left(y_{j}-\delta+\beta\right)}{u^{\prime}\left(y_{j}-\beta\right)-u^{\prime}\left(y_{j}-\delta+\beta\right)+u^{\prime}\left(y_{i}-\beta\right)-u^{\prime}\left(y_{i}-\delta+\beta\right)}
\end{aligned}
$$

Thus,

$\left\{\pi_{j}\left[u^{\prime}\left(y_{i}-\beta\right)-\lambda u^{\prime}\left(y_{j}-\delta+\beta\right)\right]+\left(1-\pi_{j}\right)\left[u^{\prime}\left(y_{i}-\delta+\beta\right)-\lambda u^{\prime}\left(y_{j}-\beta\right)\right]\right\} \neq 0$ and

$\left\{\pi_{i}\left[u^{\prime}\left(y_{j}-\beta\right)-\lambda u^{\prime}\left(y_{i}-\delta+\beta\right)\right]+\left(1-\pi_{i}\right)\left[u^{\prime}\left(y_{j}-\delta+\beta\right)-\lambda u^{\prime}\left(y_{i}-\beta\right)\right]\right\} \neq 0$.

Q.E.D.

\section{Proof for Proposition 2.}

From (11),

$$
\begin{aligned}
& \left\{\pi^{\prime \prime}\left(e_{2}^{*}\right)\left[u\left(y_{2}^{L}+I_{1}-z^{L}\right)-u\left(y_{2}^{H}+I_{1}-z^{H}\right)\right]-v^{\prime \prime}\left(e_{2}^{*}\right)\right\} d e_{2}^{*}-\left[\pi^{\prime}\left(e_{2}^{*}\right) u^{\prime}\left(y_{2}^{L}+I_{1}-z^{L}\right)\right] d z^{L} \\
& +\left[\pi^{\prime}\left(e_{2}^{*}\right) u^{\prime}\left(y_{2}^{H}+I_{1}-z^{H}\right)\right] d z^{H}+\left\{\pi^{\prime}\left(e_{2}^{*}\right)\left[u^{\prime}\left(y_{2}^{L}+I_{1}-z^{L}\right)-u^{\prime}\left(y_{2}^{H}+I_{1}-z^{H}\right)\right]\right\} d I_{1}=0
\end{aligned}
$$

Then,

$$
e_{2 z^{L}}^{*} \equiv \frac{\partial e_{2}^{*}}{\partial z^{L}}=\frac{\left[\pi^{\prime}\left(e_{2}^{*}\right) u^{\prime}\left(y_{2}^{L}+I_{1}-z^{L}\right)\right]}{\left\{\pi^{\prime \prime}\left(e_{2}^{*}\right)\left[u\left(y_{2}^{L}+I_{1}-z^{L}\right)-u\left(y_{2}^{H}+I_{1}-z^{H}\right)\right]-v^{\prime \prime}\left(e_{2}^{*}\right)\right\}}>0
$$




$$
\begin{aligned}
& e_{2 z^{H}}^{*} \equiv \frac{\partial e_{2}^{*}}{\partial z^{H}}=\frac{-\left[\pi^{\prime}\left(e_{2}^{*}\right) u^{\prime}\left(y_{2}^{H}+I_{1}-z^{H}\right)\right]}{\left\{\pi^{\prime \prime}\left(e_{2}^{*}\right)\left[u\left(y_{2}^{L}+I_{1}-z^{L}\right)-u\left(y_{2}^{H}+I_{1}-z^{H}\right)\right]-v^{\prime \prime}\left(e_{2}^{*}\right)\right\}}<0 \\
& e_{2 I_{1}}^{*} \equiv \frac{\partial e_{2}^{*}}{\partial I_{1}}=\frac{-\left\{\pi^{\prime}\left(e_{2}^{*}\right)\left[u^{\prime}\left(y_{2}^{L}+I_{1}-z^{L}\right)-u^{\prime}\left(y_{2}^{H}+I_{1}-z^{H}\right)\right]\right\}}{\left\{\pi^{\prime \prime}\left(e_{2}^{*}\right)\left[u\left(y_{2}^{L}+I_{1}-z^{L}\right)-u\left(y_{2}^{H}+I_{1}-z^{H}\right)\right]-v^{\prime \prime}\left(e_{2}^{*}\right)\right\}}<0 .
\end{aligned}
$$

Q.E.D.

\section{Proof for Proposition 3.}

From (12), using the envelope theorem, we get

$$
\begin{gathered}
\left\{\pi^{\prime \prime}\left(e_{1}^{*}\right)\left[-u\left(y_{1}^{H}\right)+\pi\left(e_{2}^{*}\right) u\left(y_{2}^{L}+I_{1}-z^{L}\right)+\left(1-\pi\left(e_{2}^{*}\right)\right) u\left(y_{2}^{H}+I_{1}-z^{H}\right)-v\left(e_{2}^{*}\right)\right]-v^{\prime \prime}\left(e_{1}^{*}\right)\right\} d e_{1}^{*} \\
-\left[\pi^{\prime}\left(e_{1}^{*}\right) \pi\left(e_{2}^{*}\right) u^{\prime}\left(y_{2}^{L}+I_{1}-z^{L}\right)\right] d z^{L}-\left[\pi^{\prime}\left(e_{1}^{*}\right)\left(1-\pi\left(e_{2}^{*}\right)\right) u^{\prime}\left(y_{2}^{H}+I_{1}-z^{H}\right)\right] d z^{H} \\
+\left\{\pi^{\prime}\left(e_{1}^{*}\right)\left[\pi\left(e_{2}^{*}\right) u^{\prime}\left(y_{2}^{L}+I_{1}-z^{L}\right)+\left(1-\pi\left(e_{2}^{*}\right)\right) u^{\prime}\left(y_{2}^{H}+I_{1}-z^{H}\right)\right]\right\} d I_{1}=0
\end{gathered}
$$

Hence,

$$
\begin{gathered}
e_{1 z^{L}}^{*} \equiv \frac{\partial e_{1}^{*}}{\partial z^{L}}=\left(\frac{1}{\Delta}\right)\left[\pi^{\prime}\left(e_{1}^{*}\right) \pi\left(e_{2}^{*}\right) u^{\prime}\left(y_{2}^{L}+I_{1}-z^{L}\right)\right]>0 \\
e_{1 z^{H}}^{*} \equiv \frac{\partial e_{1}^{*}}{\partial z^{H}}=\left(\frac{1}{\Delta}\right)\left[\pi^{\prime}\left(e_{1}^{*}\right)\left(1-\pi\left(e_{2}^{*}\right)\right) u^{\prime}\left(y_{2}^{H}+I_{1}-z^{H}\right)\right]>0 \\
e_{1 I_{1}}^{*} \equiv \frac{\partial e_{1}^{*}}{\partial I_{1}}=\left(\frac{-1}{\Delta}\right)\left\{\pi^{\prime}\left(e_{1}^{*}\right)\left[\pi\left(e_{2}^{*}\right) u^{\prime}\left(y_{2}^{L}+I_{1}-z^{L}\right)+\left(1-\pi\left(e_{2}^{*}\right)\right) u^{\prime}\left(y_{2}^{H}+I_{1}-z^{H}\right)\right]\right\}<0
\end{gathered}
$$

where

$$
\Delta=\left\{\pi^{\prime \prime}\left(e_{1}^{*}\right)\left[-u\left(y_{1}^{H}\right)+\pi\left(e_{2}^{*}\right) u\left(y_{2}^{L}+I_{1}-z^{L}\right)+\left(1-\pi\left(e_{2}^{*}\right)\right) u\left(y_{2}^{H}+I_{1}-z^{H}\right)-v\left(e_{2}^{*}\right)\right]-v^{\prime \prime}\left(e_{1}^{*}\right)\right\}
$$

Q.E.D.

\section{Proof for Corollary 1.}

$$
\frac{\partial \pi\left(e_{1}^{*}\right)}{\partial I_{1}}=\frac{\partial \pi\left(e_{1}^{*}\right)}{\partial e_{1}^{*}} \frac{\partial e_{1}^{*}}{\partial I_{1}}>0
$$

Q.E.D.

\section{Proof for Corollary 2.}

$$
\frac{\partial \pi\left(e_{2}^{*}\right)}{\partial I_{1}}=\frac{\partial \pi\left(e_{2}^{*}\right)}{\partial e_{2}^{*}} \frac{\partial e_{2}^{*}}{\partial I_{1}}>0
$$

Q.E.D. 


\section{Proof for Proposition 4.}

From the expected utility function of the IMF under contract $A$ and the assumption $I_{1} \geq \max \left(z^{H}, z^{L}\right)$, we can see that the IMF's utility is maximized when $I_{1 A}^{*}=z_{A}^{L *}=z_{A}^{H *}$, and the corresponding level of the IMF's utility is $\widehat{u}(x)$ for any value of $e_{1}$ and $e_{2}$. Then, from the assumption that $q \leq I_{1} \leq n q, y_{2}^{L} \geq z^{L}, y_{2}^{H} \geq z^{H}$, and $y_{2}^{H}>y_{2}^{L}$, we get $q \leq I_{1 A}^{*}=z_{A}^{L *}=z_{A}^{H *} \leq \min \left(n q, y_{2}^{L}\right)$.

Q.E.D.

\section{Proof for Proposition 5.}

Note that the sum of the right-hand side of $(13),(14)$ and $(15)$ is zero. Thus, if the right-hand side of (14) and (15) is negative, then the right-hand side of (13) must be positive.

Suppose $x \rightarrow \infty$ and $\theta \gg 0$. Then, the second and the third terms on the righthand side of (14) and (15) converge to zero while the first term of (14) and (15) is negative and not close to 0 . Thus, the right-hand side of (14) and (15) becomes negative, which means $z_{B}^{H *}=z_{B}^{L *}=0$ and $I_{1 B}^{*}=n q$.

Next, consider the case where $x$ is small (i.e. close to 0 ). We know that now the first and second terms on the right-hand side of (14) and (15) are positive and the first terms in (14) and (15) are close to $\infty$. Thus, the right-hand side of (14) and (15) becomes positive, which means $I_{1 B}^{*}=z_{B}^{H *}=z_{B}^{L *}=q$ as long as $q<x$.

Q.E.D.

\section{Proof for Proposition 6.}

Let $f(e) \equiv-\frac{v^{\prime}(e)}{\pi^{\prime}(e)}$, and note that $\frac{\partial f}{\partial e}=-\left[\frac{v^{\prime \prime}(e) \pi^{\prime}(e)-\pi^{\prime \prime}(e) v^{\prime}(e)}{\left\{\pi^{\prime}(e)\right\}^{2}}\right]>0$. The results in Proposition 6 follow directly from $(11), 12$ and the fact that $-\frac{v^{\prime}}{\pi^{\prime}}$ is a strictly increasing function of effort.

Q.E.D.

\section{Proof for Proposition 7.}

The proof is by contradiction. Suppose that $z_{C}^{H *} \leq z_{C}^{L *}$. Then, $\widehat{u}\left(x-I_{1}+z_{C}^{L *}\right) \geq$ $\widehat{u}\left(x-I_{1}+z_{C}^{H *}\right)$ holds, which means $\widehat{u}^{\prime}\left(x-I_{1}+z_{C}^{L *}\right) \leq \widehat{u}^{\prime}\left(x-I_{1}+z_{C}^{H *}\right)$.

Now, from 19), $\widehat{u}^{\prime}\left(x-I_{1}+z_{C}^{L}\right) \geq \theta u^{\prime}\left(y_{2}^{L}+I_{1}-z_{C}^{L}\right)$.

Also, from (20), $\widehat{u}^{\prime}\left(x-I_{1}+z_{C}^{H}\right) \leq \theta u^{\prime}\left(y_{2}^{H}+I_{1}-z_{C}^{H}\right)$.

But, from the first order condition with respect to $e_{2}, u^{\prime}\left(y_{2}^{L}+I_{1}-z_{C}^{L}\right)>u^{\prime}\left(y_{2}^{H}+\right.$ $\left.I_{1}-z_{C}^{H}\right)$.

Thus, it follows that 


$$
\widehat{u}^{\prime}\left(x-I_{1}+z_{C}^{L}\right) \geq \theta u^{\prime}\left(y_{2}^{L}+I_{1}-z_{C}^{L}\right)>\theta u^{\prime}\left(y_{2}^{H}+I_{1}-z_{C}^{H}\right) \geq \widehat{u}^{\prime}\left(x-I_{1}+z_{C}^{H}\right),
$$

which implies $\widehat{u}^{\prime}\left(x-I_{1}+z_{C}^{L}\right)>\widehat{u}^{\prime}\left(x-I_{1}+z_{C}^{H}\right)$. This is a contradiction.

Q.E.D

\section{Proof for Proposition 8 and Lemma 2.}

Throughout the proof, we denote the general expected utility of the IMF by $E U_{I M F}$, and make the following assumptions:

Assumption 1. $E U_{I M F} \in C_{2}$ (i.e. twice continuously differentiable) with respect to $T^{H}, T^{L}$ and $\kappa$, where $\kappa$ is defined in (PART 1 ) below.

This assumption is necessary for well-behaved second-order conditions.

Assumption 2. $\left\{I_{1 B}^{*}, z_{B}^{L *}, z_{B}^{H *}\right\}$ and $\left\{I_{1 C}^{*}, z_{C}^{L *}, z_{C}^{H *}\right\}$ are interior solutions.

Assumption 3. $\frac{\partial^{2} E U_{I M F}}{\partial\left(T^{i}\right)^{2}}<0, \frac{\partial^{2} E U_{I M F}}{\partial T^{i} \partial T^{j}}>0$, and $\left|\frac{\partial^{2} E U_{I M F}}{\partial\left(T^{i}\right)^{2}}\right|>\frac{\partial^{2} E U_{I M F}}{\partial T^{i} \partial T^{j}}, i, j=H, L$, $i \neq j$.

This assumption assures that the second-order condition for a maximum holds. It also guarantees that the expected utility of the IMF is more sensitive to its own wealth compared to that of the country.

The proof has two parts: the first part shows that $e_{2}^{* B}>e_{2}^{* C}, e_{1}^{* B}>e_{1}^{* C}$ and $T_{C}^{H *}>T_{B}^{H *}, T_{C}^{L *}>T_{B}^{L *}$; the second part shows that $e_{2}^{* C}>e_{2}^{* D}, e_{1}^{* C}>e_{1}^{* D}$ and $T_{C}^{H *}>T_{D}^{H *}, T_{D}^{L *}>T_{C}^{L *}$.

\section{(PART I)}

First, we show that $e_{2}^{* B}>e_{2}^{* C}$.

When we compare the IMF's expected utility functions under contracts $B$ and $C$, we find that the first order conditions, after normalization, differ only in that each of the first order conditions under contract $B$ has an additional term

$$
e_{1 i}^{*}\left\{\frac{\pi^{\prime}\left(e_{1}^{*}\right)}{\pi\left(e_{1}^{*}\right)}\left[\pi\left(e_{2}^{*}\right) \widehat{u}\left(x-I_{1}+z^{L}\right)+\left(1-\pi\left(e_{2}^{*}\right)\right) \widehat{u}\left(x-I_{1}+z^{H}\right)-\widehat{u}(x)\right]\right\},
$$

where $i=I_{1}, z^{L}, z^{H}$. Thus, we can represent the solution of the problem under both the contracts in one system of equations using the following term

$$
\kappa e_{1 i}^{*}\left\{\frac{\pi^{\prime}\left(e_{1}^{*}\right)}{\pi\left(e_{1}^{*}\right)}\left[\pi\left(e_{2}^{*}\right) \widehat{u}\left(x-I_{1}+z^{L}\right)+\left(1-\pi\left(e_{2}^{*}\right)\right) \widehat{u}\left(x-I_{1}+z^{H}\right)-\widehat{u}(x)\right]\right\}
$$


where $i=I_{1}, z^{L}, z^{H}$. For $\kappa=0$, we get the appropriate conditions for contract $C$, and for $\kappa=1$, we get them for contract $B$.

To show that $e_{2}^{* B}>e_{2}^{* C}$, first we derive the change of $z^{H}, z^{L}$, and $I_{1}$ when we move from contract $B$ to contract $C$, then we calculate the change of $e_{2}^{*}$ due to the changes in $z^{H}, z^{L}$, and $I_{1}$ between the two contracts, and finally we combine these two effects to get the total effect.

In particular, define $F=\frac{\partial E U_{I M F}}{\partial I_{1}}, G=\frac{\partial E U_{I M F}}{\partial z^{L}}, H=\frac{\partial E U_{I M F}}{\partial z^{H}}$.

Then, we need to solve the following system of equations to get $\frac{\partial I_{1}}{\partial \kappa}, \frac{\partial z^{L}}{\partial \kappa}$, and $\frac{\partial z^{H}}{\partial \kappa}$ :

$$
\left[\begin{array}{lll}
F_{1} & F_{2} & F_{3} \\
G_{1} & G_{2} & G_{3} \\
H_{1} & H_{2} & H_{3}
\end{array}\right]\left[\begin{array}{l}
d I_{1} \\
d z^{L} \\
d z^{H}
\end{array}\right]=\left[\begin{array}{l}
-F_{4} \\
-G_{4} \\
-H_{4}
\end{array}\right] d \kappa
$$

where $F_{1}=\frac{\partial F}{\partial I_{1}}, F_{2}=\frac{\partial F}{\partial z^{L}}, F_{3}=\frac{\partial F}{\partial z^{H}}, F_{4}=\frac{\partial F}{\partial \kappa}$, and so on.

Thus, we need to show that

$$
\int_{0}^{1} \frac{\partial I_{1}}{\partial \kappa} \frac{\partial e_{2}^{*}}{\partial I_{1}} d \kappa+\int_{0}^{1} \frac{\partial z^{L}}{\partial \kappa} \frac{\partial e_{2}^{*}}{\partial z^{L}} d \kappa+\int_{0}^{1} \frac{\partial z^{H}}{\partial \kappa} \frac{\partial e_{2}^{*}}{\partial z^{H}} d \kappa>0
$$

holds.

Note that $F+G+H=0, \forall I_{1}, z^{L}, z^{H}, \kappa$. Thus, from Assumption 2, one of the terms $F, G$ or $H$ is redundant. Therefore, we can redefine the problem as a 2equation-2-variable problem using the following change of variables: $T^{H} \equiv I_{1}-z^{H}$ and $T^{L} \equiv I_{1}-z^{L}$, where $T^{H}, T^{L} \geq 0$ from the assumption that $I_{1}-\max \left(z^{H}, z^{L}\right) \geq 0$. Now we can rewrite the IMF's expected utility functions under contracts $B$ and $C$ using $T^{H}, T^{L}$, calculate the derivatives $e_{1 T^{H}}^{*}, e_{1 T^{L}}^{*}, e_{2 T^{H}}^{*}, e_{2 T^{L}}^{*}$, and redefine $F$ and $G$ as follows:

$$
\begin{aligned}
F & \equiv \frac{\partial E U_{I M F}}{\partial T^{H}} \\
& =\left[1-\pi\left(e_{2}^{*}\right)\right]\left[-\widehat{u}^{\prime}\left(x-T^{H}\right)+\theta u^{\prime}\left(y_{2}^{H}+T^{H}\right)\right]+e_{2 T^{H}}^{*}\left\{\pi^{\prime}\left(e_{2}^{*}\right)\left[\widehat{u}\left(x-T^{L}\right)-\widehat{u}\left(x-T^{H}\right)\right]\right\} \\
& +\kappa e_{1 T^{H}}^{*}\left\{\frac{\pi^{\prime}\left(e_{1}^{*}\right)}{\pi\left(e_{1}^{*}\right)}\left[\pi\left(e_{2}^{*}\right) \widehat{u}\left(x-T^{L}\right)+\left(1-\pi\left(e_{2}^{*}\right)\right) \widehat{u}\left(x-T^{H}\right)-\widehat{u}(x)\right]\right\} \\
G & \equiv \frac{\partial E U_{I M F}}{\partial T^{L}} \\
& =\pi\left(e_{2}^{*}\right)\left[-\widehat{u}^{\prime}\left(x-T^{L}\right)+\theta u^{\prime}\left(y_{2}^{L}+T^{L}\right)\right]+e_{2 T^{L}}^{*}\left\{\pi^{\prime}\left(e_{2}^{*}\right)\left[\widehat{u}\left(x-T^{L}\right)-\widehat{u}\left(x-T^{H}\right)\right]\right\} \\
& +\kappa e_{1 T^{L}}^{*}\left\{\frac{\pi^{\prime}\left(e_{1}^{*}\right)}{\pi\left(e_{1}^{*}\right)}\left[\pi\left(e_{2}^{*}\right) \widehat{u}\left(x-T^{L}\right)+\left(1-\pi\left(e_{2}^{*}\right)\right) \widehat{u}\left(x-T^{H}\right)-\widehat{u}(x)\right]\right\}
\end{aligned}
$$

Note that $E U_{I M F}=E U_{I M F}\left(T^{H}, T^{L}, \kappa\right)$. Thus, from Assumption 1, we have $F=$ 
$F\left(T^{H}, T^{L}, \kappa\right)$ and $G=G\left(T^{H}, T^{L}, \kappa\right)$.

To show that $e_{2}^{* B}>e_{2}^{* C}$, we need to show that $\int_{0}^{1} \frac{\partial T^{L}}{\partial \kappa} \frac{\partial e_{2}^{*}}{\partial T^{L}} d \kappa+\int_{0}^{1} \frac{\partial T^{H}}{\partial \kappa} \frac{\partial e_{2}^{*}}{\partial T^{H}} d \kappa>0$ holds, where the first term on the left side of the inequality represents the increase in $e_{2}^{*}$ through $T^{L}$ when we move from contract $C$ to $B$, and the second term represents the decrease in $e_{2}^{*}$ through $T^{H}$ when we move from contract $C$ to $B$. To this end, it is sufficient to show that $\frac{\partial T^{L}}{\partial \kappa} \frac{\partial e_{2}^{*}}{\partial T^{L}}+\frac{\partial T^{H}}{\partial \kappa} \frac{\partial e_{2}^{*}}{\partial T^{H}}>0$.

To derive $\frac{\partial T^{L}}{\partial \kappa}$ and $\frac{\partial T^{H}}{\partial \kappa}$, we differentiate $F$ and $G$ with respect to $T^{H}, T^{L}, \kappa$ and get the following:

$$
\left[\begin{array}{ll}
F_{1} & F_{2} \\
G_{1} & G_{2}
\end{array}\right]\left[\begin{array}{l}
d T^{H} \\
d T^{L}
\end{array}\right]=\left[\begin{array}{l}
-F_{3} \\
-G_{3}
\end{array}\right] d \kappa
$$

where $F_{1}=\frac{\partial F}{\partial T^{H}}, F_{2}=\frac{\partial F}{\partial T^{L}}, F_{3}=\frac{\partial F}{\partial \kappa}$, and so on.

Since $F_{1}, F_{2}, F_{3}, G_{1}, G_{2}, G_{3}$ are continuous, by Young's theorem, $F_{2}=G_{1}$. We can also show that $F_{3}<0$ and $G_{3}<0$.

From Assumption 3, we get $\left|\begin{array}{cc}F_{1} & F_{2} \\ G_{1} & G_{2}\end{array}\right|=F_{1} G_{2}-F_{2} G_{1}>0$. Denote $\left|\begin{array}{cc}F_{1} & F_{2} \\ G_{1} & G_{2}\end{array}\right|$ as $|J|$. Then, $\frac{\partial T^{L}}{\partial \kappa}=\frac{-F_{1} G_{3}+F_{3} G_{1}}{|J|}<0$ and $\frac{\partial T^{H}}{\partial \kappa}=\frac{-F_{3} G_{2}+F_{2} G_{3}}{|J|}<0$.

It follows that $T_{C}^{H *}>T_{B}^{H *}$ and $T_{C}^{L *}>T_{B}^{L *}$.

To prove Lemma 2, first note that

$$
\begin{aligned}
\frac{\partial e_{1}^{*}}{\partial T^{H}} & =\frac{-\left[\pi^{\prime}\left(e_{1}^{*}\right)\left(1-\pi\left(e_{2}^{*}\right)\right) u^{\prime}\left(y_{2}^{H}+T^{H}\right)\right]}{\left\{\pi^{\prime \prime}\left(e_{1}^{*}\right)\left[-u\left(y_{1}^{H}\right)+\pi\left(e_{2}^{*}\right) u\left(y_{2}^{L}+T^{L}\right)+\left(1-\pi\left(e_{2}^{*}\right)\right) u\left(y_{2}^{H}+T^{H}\right)-v\left(e_{2}^{*}\right)\right]-v^{\prime \prime}\left(e_{1}^{*}\right)\right\}}<0 \\
\frac{\partial e_{1}^{*}}{\partial T^{L}} & =\frac{-\left[\pi^{\prime}\left(e_{1}^{*}\right) \pi\left(e_{2}^{*}\right) u^{\prime}\left(y_{2}^{L}+T^{L}\right)\right]}{\left\{\pi^{\prime \prime}\left(e_{1}^{*}\right)\left[-u\left(y_{1}^{H}\right)+\pi\left(e_{2}^{*}\right) u\left(y_{2}^{L}+T^{L}\right)+\left(1-\pi\left(e_{2}^{*}\right)\right) u\left(y_{2}^{H}+T^{H}\right)-v\left(e_{2}^{*}\right)\right]-v^{\prime \prime}\left(e_{1}^{*}\right)\right\}}<0
\end{aligned}
$$

Since we already know, from the first-order condition of $P$ with respect to $e_{2}$, that $u^{\prime}\left(y_{2}^{L}+T^{L}\right)>u^{\prime}\left(y_{2}^{H}+T^{H}\right)$, once we have $\pi\left(e_{2}^{*}\right) \geq 1 / 2$, then $\frac{\partial e_{1}^{*}}{\partial T^{L}}<\frac{\partial e_{1}^{*}}{\partial T^{H}}<0$ holds. Therefore, Lemma 2 is true.

By Lemma 2, $\left|G_{3}\right|>\left|F_{3}\right|$. Using Assumption 4, $F_{1} \approx G_{2}$, we have $\left(F_{1}+F_{2}\right) G_{3} \geq$ $\left(G_{1}+G_{2}\right) F_{3}$, and hence $\left|\frac{\partial T^{L}}{\partial \kappa}\right| \geq\left|\frac{\partial T^{H}}{\partial \kappa}\right|$. Then, together with $0<e_{2 T^{H}}^{*}<\left|e_{2 T^{L}}^{*}\right|$ we have from the first-order condition of $P$, we get $\frac{\partial T^{L}}{\partial \kappa} \frac{\partial e_{2}^{*}}{\partial T^{L}}+\frac{\partial T^{H}}{\partial \kappa} \frac{\partial e_{2}^{*}}{\partial T^{H}}>0$. Therefore, $e_{2}^{* B}>e_{2}^{* C}$.

Second, given $e_{2}^{* B}>e_{2}^{* C}$ and $T_{C}^{H *}>T_{B}^{H *}, T_{C}^{L *}>T_{B}^{L *}$, we have to show that $e_{1}^{* B}>e_{1}^{* C}$. Now denote the variables in the case of contract $C$ by . For example, $\widetilde{\pi}^{1 \prime} \equiv \pi^{\prime}\left(e_{1}^{* C}\right)$ and $\widetilde{v}^{2} \equiv v\left(e_{2}^{* C}\right)$.

Solving for the surveillance country's choice of $e_{1}$ under contract $C$, given $\left(T_{C}^{H *}, T_{C}^{L *}, e_{2}^{* C}\right)$, 
we get

$$
\widetilde{\pi}^{1 \prime}\left[-u\left(y_{1}^{H}\right)+\widetilde{\pi}^{2} u\left(y_{2}^{L}+T_{C}^{L *}\right)+\left(1-\widetilde{\pi}^{2}\right) u\left(y_{2}^{H}+T_{C}^{H *}\right)-\widetilde{v}^{2}\right]=\widetilde{v}^{1 \prime}
$$

Rearranging terms,

$$
-\widetilde{\pi}^{2} u\left(y_{2}^{L}+T_{C}^{L *}\right)-\left(1-\widetilde{\pi}^{2}\right) u\left(y_{2}^{H}+T_{C}^{H *}\right)+u\left(y_{1}^{H}\right)+\widetilde{v}^{2}=-\frac{\widetilde{v}^{1 \prime}}{\widetilde{\pi}^{1 \prime}}>0 .
$$

Proceeding similarly for contract $B$, we show

$$
-\pi^{2} u\left(y_{2}^{L}+T_{B}^{L *}\right)-\left(1-\pi^{2}\right) u\left(y_{2}^{H}+T_{B}^{H *}\right)+u\left(y_{1}^{H}\right)+v^{2}=-\frac{v^{1 \prime}}{\pi^{1 \prime}}>0 .
$$

Note $v$ and $\widetilde{v}$ are positive unless $e^{*}$ 's are corner solutions; and from the assumption that $y_{1}^{H}>\max \left[y_{2}^{L}+I_{1}-z^{L}, y_{2}^{H}+I_{1}-z^{H}\right]$, it follows that $-\frac{\widetilde{v}^{1 \prime}}{\widetilde{\pi}^{1 \prime}}$ and $-\frac{v^{1 \prime}}{\pi^{1 \prime}}$ are indeed positive.

Let $f\left(e_{1}\right) \equiv-\frac{v^{\prime}\left(e_{1}\right)}{\pi^{\prime}\left(e_{1}\right)}$, and note that $\frac{\partial f}{\partial e_{1}}=-\left[\frac{v^{\prime \prime}\left(e_{1}\right) \pi^{\prime}\left(e_{1}\right)-\pi^{\prime \prime}\left(e_{1}\right) v^{\prime}\left(e_{1}\right)}{\left\{\pi^{\prime}\left(e_{1}\right)\right\}^{2}}\right]>0$. Thus, $f$ is strictly increasing in $e_{1}$, which implies that, if $-\frac{\widetilde{v}^{1 \prime}}{\widetilde{\pi}^{1 \prime}}<-\frac{v^{1 \prime}}{\pi^{1 \prime}}$, then $e_{1}^{* B}>e_{1}^{* C}$. But Assumption 5, $E U_{P}\left(T_{B}^{H *}, T_{B}^{L *}, e_{2}^{* B}\right)<E U_{P}\left(T_{C}^{H *}, T_{C}^{L *}, e_{2}^{* C}\right)$, is equivalent to $-\frac{\widetilde{v}^{1 \prime}}{\widetilde{\pi}^{1 \prime}}<$ $-\frac{v^{1 \prime}}{\pi^{1 \prime}}$. Hence, $e_{1}^{* B}>e_{1}^{* C}$.

\section{(PART II)}

First, consider the choice of $T_{C}^{H *}$ and $T_{C}^{L *}$ by the IMF under contract $C$.

The first-order conditions with respect to $T_{C}^{H}$ and $T_{C}^{L}$ are:

$$
\begin{gathered}
-\pi\left(e_{2}^{*}\right)\left[\widehat{u}^{\prime}\left(x-T^{L}\right)-\theta u^{\prime}\left(y_{2}^{L}+T^{L}\right)\right]+e_{2 T^{L}}^{*}\left\{\pi^{\prime}\left(e_{2}^{*}\right)\left[\widehat{u}\left(x-T^{L}\right)-\widehat{u}\left(x-T^{H}\right)\right]\right\}=0 \\
-\left[1-\pi\left(e_{2}^{*}\right)\right]\left[\widehat{u}^{\prime}\left(x-T^{H}\right)-\theta u^{\prime}\left(y_{2}^{H}+T^{H}\right)\right]+e_{2 T^{H}}^{*}\left\{\pi^{\prime}\left(e_{2}^{*}\right)\left[\widehat{u}\left(x-T^{L}\right)-\widehat{u}\left(x-T^{H}\right)\right]\right\}=0
\end{gathered}
$$

We know from Proposition 7 that $T_{C}^{H *}<T_{C}^{L *}$. From the above first-order conditions, we get the following inequalities:

$$
\begin{aligned}
& \widehat{u}^{\prime}\left(x-T_{C}^{L *}\right)-\theta u^{\prime}\left(y_{2}^{L}+T_{C}^{L *}\right)<0 \\
& \widehat{u}^{\prime}\left(x-T_{C}^{H *}\right)-\theta u^{\prime}\left(y_{2}^{H}+T_{C}^{H *}\right)>0
\end{aligned}
$$


Next, consider the choice of $T_{D}^{H}$ and $T_{D}^{L}$ by the IMF under contract $D$. The firstorder conditions with respect to $T_{D}^{H}$ and $T_{D}^{L}$ are:

$$
\begin{aligned}
& \widehat{u}^{\prime}\left(x-T_{D}^{L *}\right)=\theta u^{\prime}\left(y_{2}^{L}+T_{D}^{L *}\right) \\
& \widehat{u}^{\prime}\left(x-T_{D}^{H *}\right)=\theta u^{\prime}\left(y_{2}^{H}+T_{D}^{H *}\right)
\end{aligned}
$$

Comparing (iii) and (v), we see that $T_{C}^{L *}<T_{D}^{L *}$. Also, a comparison of (iv) and (vi) reveals that $T_{C}^{H *}>T_{D}^{H *}$. Therefore, we have

$$
T_{D}^{L *}>T_{C}^{L *}>T_{C}^{H *}>T_{D}^{H *}
$$

Now, we need to show $e_{2}^{* C}>e_{2}^{* D}$. Given $\left(T_{D}^{H *}, T_{D}^{L *}\right)$ already chosen by the IMF, the program country, $P$, chooses $e_{2}^{* D}$ that satisfies

$$
\pi^{\prime}\left(e_{2}^{* D}\right)\left[u\left(y_{2}^{L}+T_{D}^{L *}\right)-u\left(y_{2}^{H}+T_{D}^{H *}\right)\right]=v^{\prime}\left(e_{2}^{* D}\right) .
$$

Rearranging terms, we have

$$
u\left(y_{2}^{H}+T_{D}^{H *}\right)-u\left(y_{2}^{L}+T_{D}^{L *}\right)=-\frac{v^{\prime}\left(e_{2}^{* D}\right)}{\pi^{\prime}\left(e_{2}^{* D}\right)} .
$$

Similarly, given $\left(T_{C}^{H *}, T_{C}^{L *}\right)$, the program country chooses $e_{2}^{* C}$ that satisfies

$$
u\left(y_{2}^{H}+T_{C}^{H *}\right)-u\left(y_{2}^{L}+T_{C}^{L *}\right)=-\frac{v^{\prime}\left(e_{2}^{* C}\right)}{\pi^{\prime}\left(e_{2}^{* C}\right)} .
$$

Note that from (vii), we have $u\left(y_{2}^{H}+T_{C}^{H *}\right)>u\left(y_{2}^{H}+T_{D}^{H *}\right)$ and $u\left(y_{2}^{L}+T_{C}^{L *}\right)<$ $u\left(y_{2}^{L}+T_{D}^{L *}\right)$. Thus, $u\left(y_{2}^{H}+T_{D}^{H *}\right)-u\left(y_{2}^{L}+T_{D}^{L *}\right)<u\left(y_{2}^{H}+T_{C}^{H *}\right)-u\left(y_{2}^{L}+T_{C}^{L *}\right)$, which is equivalent to

$$
-\frac{v^{\prime}\left(e_{2}^{* C}\right)}{\pi^{\prime}\left(e_{2}^{* C}\right)}>-\frac{v^{\prime}\left(e_{2}^{* D}\right)}{\pi^{\prime}\left(e_{2}^{* D}\right)}
$$

Let $\widehat{g}\left(e_{2}\right) \equiv-\frac{v^{\prime}\left(e_{2}\right)}{\pi^{\prime}\left(e_{2}\right)}>0$, and note that $\frac{\partial \widehat{g}}{\partial e_{2}}>0$. Thus, $\widehat{g}$ is strictly increasing in $e_{2}$, which implies that $e_{2}^{* C}>e_{2}^{* D}$. 
Finally, we need to show $e_{1}^{* C}>e_{1}^{* D}$ given $e_{2}^{* C}>e_{2}^{* D}$ and $T_{D}^{L *}>T_{C}^{L *}>T_{C}^{H *}>$ $T_{D}^{H *}$.

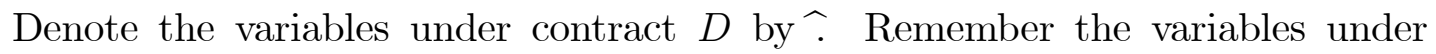
contract $C$ are given by .

Given $\left(e_{2}^{* D}, T_{D}^{L *}, T_{D}^{H *}\right)$, solving for the surveillance country's choice of $e_{1}$ under contract $D$ case, we get

$$
\widehat{\pi}^{1 \prime}\left[-u\left(y_{1}^{H}\right)+\widehat{\pi}^{2} u\left(y_{2}^{L}+T_{D}^{L *}\right)+\left(1-\widehat{\pi}^{2}\right) u\left(y_{2}^{H}+T_{D}^{H *}\right)-\widehat{v}^{2}\right]=\widehat{v}^{1 \prime} .
$$

Rearranging terms, gives

$$
-\widehat{\pi}^{2} u\left(y_{2}^{L}+T_{D}^{L *}\right)-\left(1-\widehat{\pi}^{2}\right) u\left(y_{2}^{H}+T_{D}^{H *}\right)+u\left(y_{1}^{H}\right)+\widehat{v}^{2}=-\frac{\widehat{v}^{1 \prime}}{\widehat{\pi}^{1 \prime}}>0 .
$$

Similarly, for contract $C$, we get

$$
-\widetilde{\pi}^{2} u\left(y_{2}^{L}+T_{C}^{L *}\right)-\left(1-\widetilde{\pi}^{2}\right) u\left(y_{2}^{H}+T_{C}^{H *}\right)+u\left(y_{1}^{H}\right)+\widetilde{v}^{2}=-\frac{\widetilde{v}^{1 \prime}}{\widetilde{\pi}^{1 \prime}}>0 .
$$

Now let $\widehat{f} \equiv-\frac{v^{\prime}\left(e_{1}\right)}{\pi^{\prime}\left(e_{1}\right)}$, and note that $\frac{\partial \widehat{f}}{\partial e_{1}}=-\left[\frac{v^{\prime \prime}\left(e_{1}\right) \pi^{\prime}\left(e_{1}\right)-\pi^{\prime \prime}\left(e_{1}\right) v^{\prime}\left(e_{1}\right)}{\left\{\pi^{\prime}\left(e_{1}\right)\right\}^{2}}\right]>0$. Thus, $\widehat{f}$ is strictly increasing in $e_{1}$, which implies that, if $-\frac{\widetilde{v}^{1 \prime}}{\widetilde{\pi}^{1 \prime}}>-\frac{\widehat{v}^{1 \prime}}{\widehat{\pi}^{1 \prime}}$, then $e_{1}^{* C}>e_{1}^{* D}$. But Assumption 5, $E U_{P}\left(T_{C}^{H *}, T_{C}^{L *}, e_{2}^{* C}\right)<E U_{P}\left(T_{D}^{H *}, T_{D}^{L *}, e_{2}^{* D}\right)$, is equivalent to $-\frac{\widetilde{v}^{1 \prime}}{\widetilde{\pi}^{1 \prime}}>$ $-\frac{\widehat{v}^{1 \prime}}{\widehat{\pi}^{1 \prime}}$. Hence, $e_{1}^{* C}>e_{1}^{* D}$.

Q.E.D. 


\section{References}

Becker, G. S. (1974). A Theory of Social Interaction. Journal of Political Economy 82: 1063-93.

Bergstrom, T. C. (1989). A Fresh Look at the Rotten Kid Theorem-and Other Household Mysteries. Journal of Political Economy 97: 1138-1159.

Bernheim, D., A. Shleifer, and L. E. Summers (1985). The Strategic Bequest Motive. Journal of Political Economy 93: 1045-1076.

Bernheim, D., and O. Stark (1988). Altruism within the Family Reconsidered: Do Nice Guys Finish Last? American Economic Review 78: 1034-1045.

Bird, G. (2007). The IMF: A Bird's Eye View of its Role and Operations. Journal of Economic Surveys 21: 683-745.

Bordo, M. D., and A. J. Schwartz (1999). Under What Circumstances, Past and Present, Have International Rescues of Countries in Financial Distress Been Successful? Journal of International Money and Finance 18: 683-708.

Boughton, J. M. (2004). The IMF and the Force of History: Ten Events and Ten Ideas that have Shaped the Institution. IMF Working Paper 04/75. International Monetary Fund.

Bruce, N., and M. Waldman (1990). The Rotten Kid Theorem Meets the Samaritan's Dilemma. Quarterly Journal of Economics 105: 155-165.

Buchanan, J. M. (1975). The Samaritan's Dilemma. In E. S. Phelps (eds.), Altruism, Morality and Economic Theory. New York: Russel Sage Foundation. pp. $71-85$.

Calomiris, C. W. (1999). How to Invent a New IMF. Washington: American Enterprise Institute.

Capie, F. (1998). Can There be an International Lender-of-Last-Resort? International Finance 1: 311-325.

Chami, R. (1996). King Lear's Dilemma: Precommitment versus the Last Word. Economics Letters 52: 171-176.

(1998). Private Income Transfers and Market Incentives. Economica 65: $557-580$. 
and J. H. Fischer (1996). Altruism, Matching and Nonmarket Insurance. Economic Inquiry 34: 630-647.

Cordella, T., and E. Levy-Yeyati (2004). Country Insurance. IMF Working Paper 04/148. International Monetary Fund.

Cox, D. (1987). Motives for Private Income Transfers. Journal of Political Economy 95: $508-546$.

Council on Foreign Relations (1999). Safeguarding Prosperity in a Global Financial System: The Future International Financial Architecture. Report of an Independent Task Force. New York: Council on Foreign Relations.

Drazen, A., and S. Fischer (1997). Conditionality and Selectivity in Lending by International Financial Institutions. mimeo. International Monetary Fund.

Eichengreen, B. (1999). Towards a New International Financial Architecture. Washington: Institute for International Economics.

Eldar, O. (2006). Reform of IMF Conditionality - A Proposal for Self-Imposed Conditionality, New York University Law and Economics Working Papers 39.

Fischer, S. (1999). On the Need for an International Lender of Last Resort. Journal of Economic Perspective 13: 85-104.

Goldstein, M. (2000). Strengthening the International Financial Architecture: Where Do We Stand? Washington: Institute for International Economics.

Ghosh, A., T. Lane, M. Schulze-Ghattas, A. Bulir, J. Hamann, and A. Mourmouras (2002). IMF-Supported Programs in Capital Account Crises. Occasional Paper 210. Washington: International Monetary Fund.

Haldane, A., and M. Kruger (2001). The Resolution of International Financial Crises. Financial Stability Review. Bank of England. December. 193-202.

Haldane, A., and A. Taylor (2003). Moral Hazard: How Does IMF Lending Affect Debtor and Creditor Incentives? Financial Stability Review. Bank of England. June. 122-133.

Hirshleifer, J. (1977). Shakespeare vs. Becker on Altruism: The Importance of Having the Last Word. Journal of Economic Literature 15: 500-502.

Holmstrőm, B. (1982). Moral Hazard in Teams. Bell Journal of Economics 13: $324-340$. 
Hovaguimian, C. (2003). The Catalytic Effect of IMF Lending. Financial Stability Review, Bank of England. December. 160-169.

Independent Evaluation Office (2003) The IMF and Recent Capital Account Crises: Indonesia, Korea and Brazil. Washington: International Monetary Fund.

Jeanne, O, and C. Wyplosz (2001). The International Lender of Last Resort: How Large is Large Enough? IMF Working Paper 01/76. International Monetary Fund.

Jeanne, O., and J. Zettlemeyer (2001). International Bailouts, Moral Hazard and Conditionality. Economic Policy October: 409-432.

Jurges, H. (2000). Of Rotten Kids and Rawlsian Parents: The Optimal Timing of Intergenerational Transfers. Journal of Population Economics 13: 147-157.

Khan, M. S., and S. Sharma (2003). IMF Conditionality and Country Ownership of Programs. World Bank Research Observer 18 (Fall): 227-248.

Krueger, A. O. (1998). Whither the World Bank and the IMF. Journal of Economic Literature 36: 1983-2020.

Kydland, F. E., and E. C. Prescott (1977). Rules Rather than Discretion: The Inconsistency of Optimal Plans. Journal of Political Economy 85: 473-92.

Laffont, J-J., and D. Martimort (2002). The Theory of Incentives: The PrincipalAgent Model.Princeton: Princeton University Press.

Lee, J. (2004). Insurance Value of International Reserves: An Option Pricing Approach. mimeo. International Monetary Fund.

Lindbeck, A., and J. W. Weibull (1988). Altruism and Time Consistency: The Economics of Fait Accompli. Journal of Political Economy 96: 1165-1182.

Masson, P. R., and M. Mussa (1995). The Role of the IMF: Financing and Its Interactions with Adjustment and Surveillance. IMF Pamphlet Series 50. Washington: International Monetary Fund.

Meltzer, A., C. F. Bergsten, C. W. Calomiris, T. Campbell, E. J. Feulner, W. L. Hoskins, R. L. Huber, M. H. Johnson, J. I. Levinson, J. D. Sachs, and E. E. Torres (2000) Results and Recommendations of the International Financial Institutions Advisory Commission. Final report to the U.S. Congress and Department of Treasury. Washington, D.C. 
Mussa, M. (1999). Reforming the International Financial Architecture: Limiting Moral Hazard and Containing Real Hazard. Reserve Bank of Australia Conference on Capital Flows and the International Financial System.

Rajan, R. G., and L. Zingales (2000). The Tyranny of Inequality. Journal of Public Economics 76: 521-558.

Stone, R. W. (2004). The Political Economy of IMF Lending in Africa, American Political Science Review 98: 577-591.

Tirole, J. (2002). Financial Crises, Liquidity, and the International Monetary System. Princeton: Princeton University Press.

U.S. Treasury (2000). Response to the Report of the International Financial Institution Advisory Commission. Washington: U.S. Treasury. 
Please note:

You are most sincerely encouraged to participate in the open assessment of this article. You can do so by either rating the article on a scale from 5 (excellent) to 1 (bad), by recommending the article, or by posting your comments.

Please go to:

www.economics-ejournal.org/economics/journalarticles/2008-14

The Editor 